
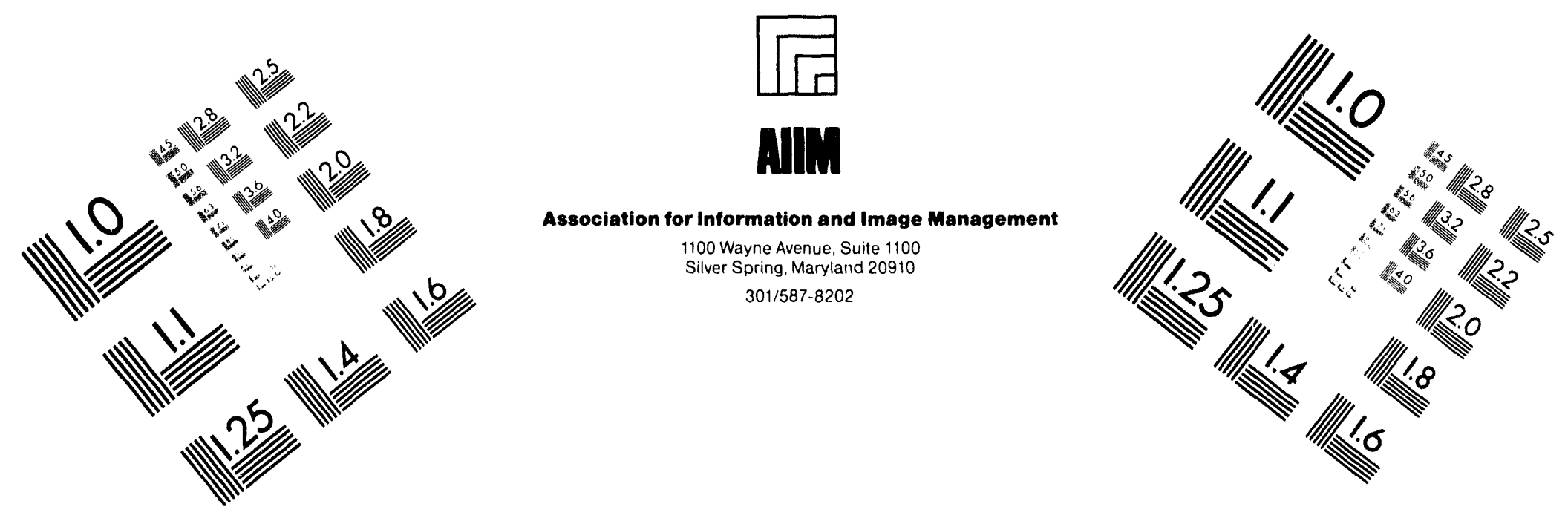

\title{
Centimeter
}

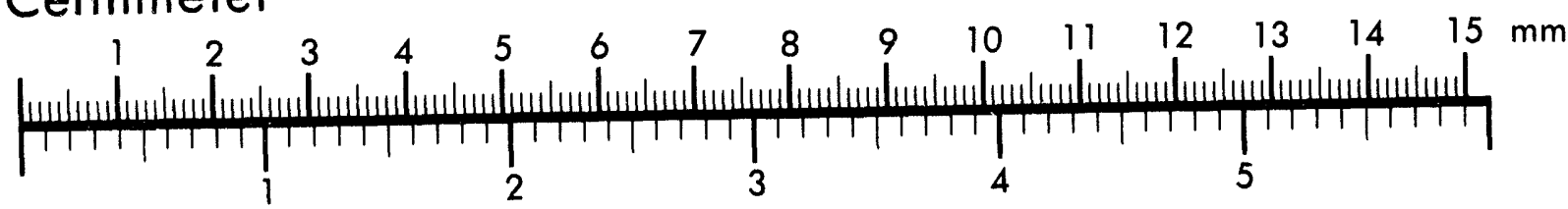
Inches
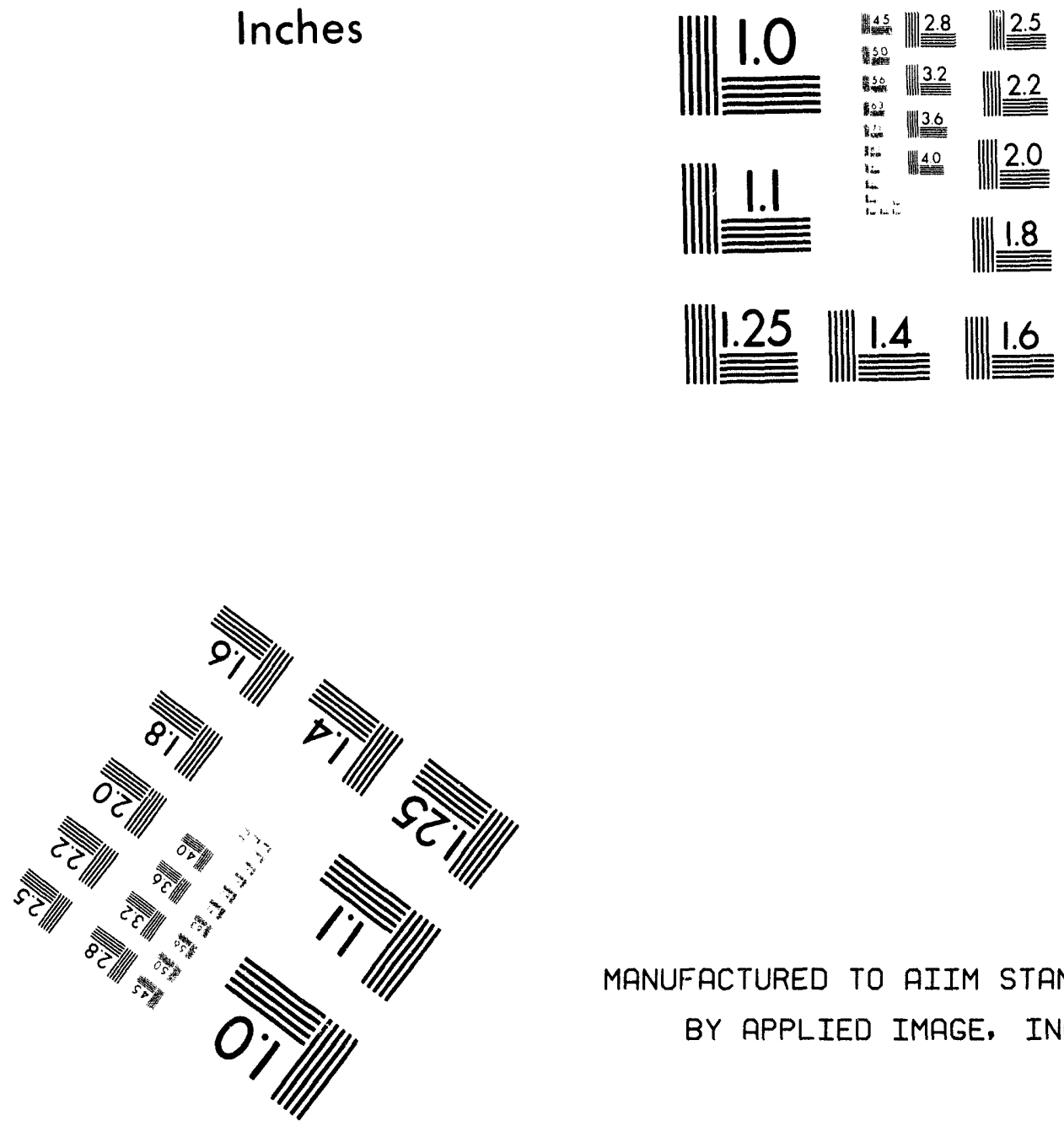

MANUFACTURED TO AIIM STANDARDS

BY APPLIED IMAGE, INC.

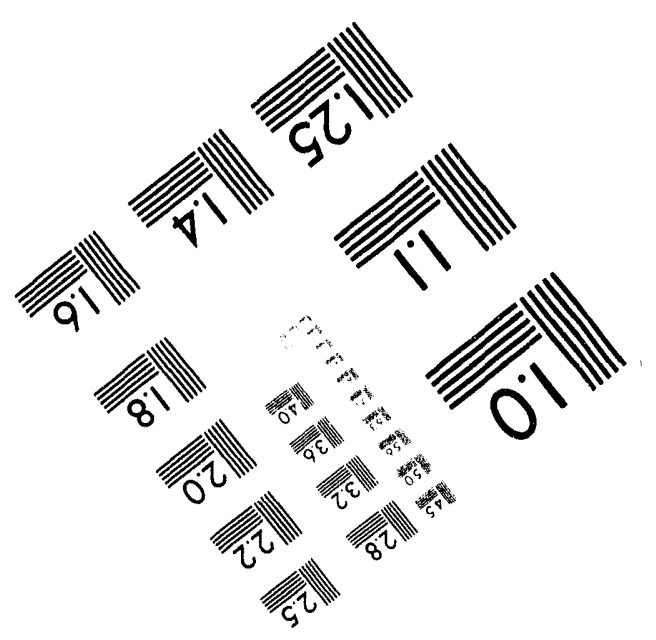



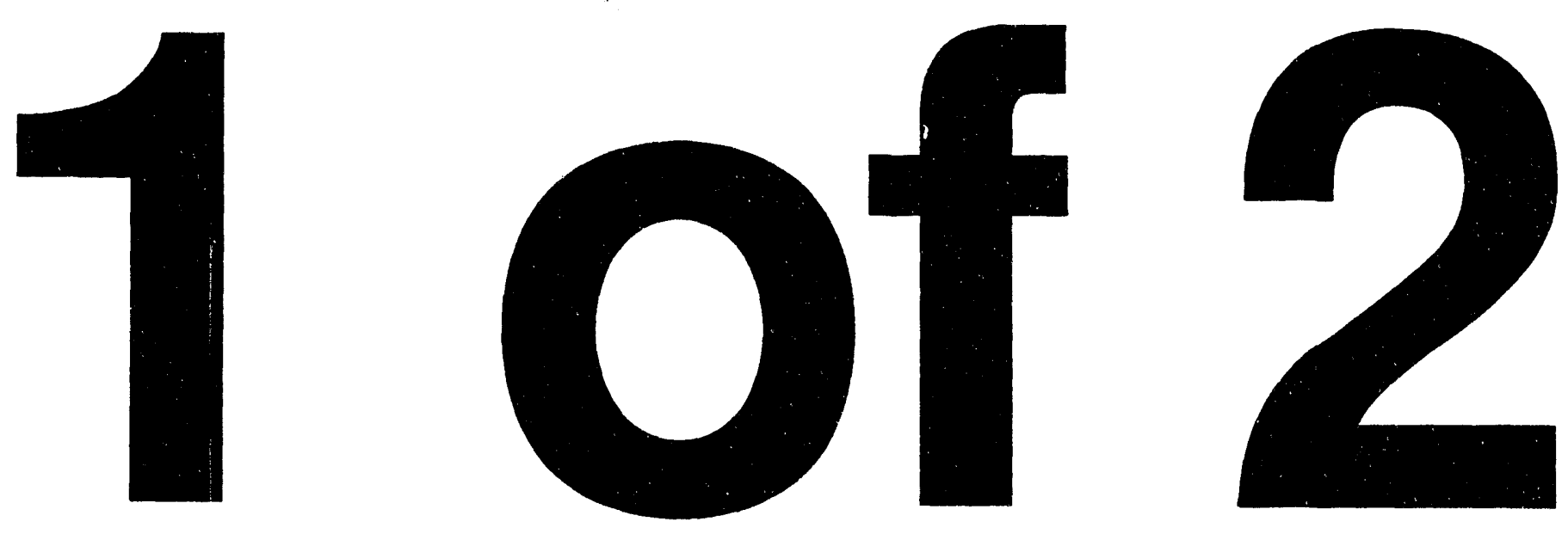
DOE/RL-93-24-8

UC. $510,702,705,721$

\section{Hanford Environmental Information System (HEIS) Volume 8 Tank Characterization Data (TCD) Subject Area}

Date Published January 1994

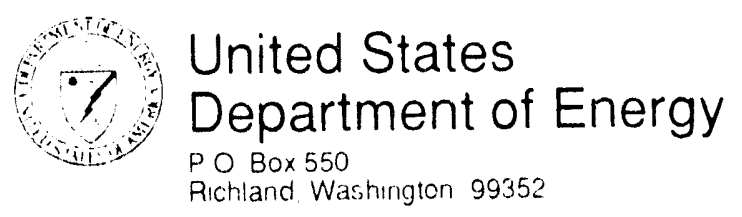

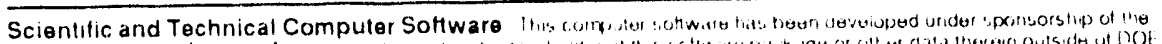

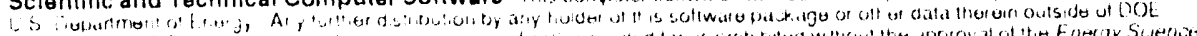

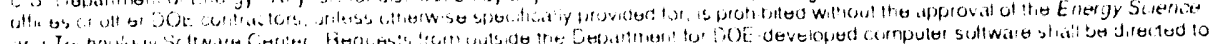

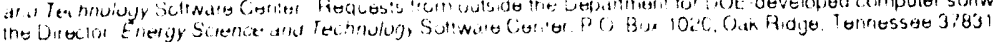




\section{LEGAL DISCLAIMER}

This reporl was orepared as an accouni of work sponsored by an agency of the United States Government. Neither the Uniled Stales Government nor any agency inereoi, nor any of their employees. nor any of their contraciors, subcontractors or their employees, makes any warranty, express or implied. or assumes any legal liability or responsibility for the accuracy, completeness, or any third party's use or the results of such use of any information, apparatus. product. or process disclosed. or represents that its us $\theta$ would not intringe privately owned fights. Reference herein 10 any specific commercial oroduct, process, or service by trade name trademark, manufacturer, or otherwise, does nol necessarily constilute or imply its endorsement, recommendation, or favoring by the United States Government or any agency thereof or its contraciors or suocontractors. The views and opinions of authors expressed herein do not necessarly state or reflecl those of the United Slates Government or any agency thereot.

This report has been reproduced from the dest avallable copy. Avaılable in paper copy and microficne.

Availabie to the U.S. Department of Energy

and is contractors lrom

Office of Scienulfic and Technical Information

PO. $80 \times 62$

Oak Ridge. TN 37831

(615) 576.8401

Avallable to the public from the U.S. Deparlment of Commerce National Technical Informalion Service

5285 Port Roya! Road

Soringfield. VA $2216 i$

(703) 487.4650

Princed in the Unilod Stalos of America 


\section{DOE/RL-93-24-8}

\section{ACKNOWLEDGMENTS}

The following staff members of the Pacific Northwest Laboratory were the primary architects and major contributors to the Tank Characterization Data volume:

S. F. Bobrowski, Task Leader

P. J. Cowley

K. A. Cook

J. S. Littlefield

J. W. Brothers

S. J. Harris

J. J. Jou

D. C. Johnson

The following staff members of Westinghouse Hanford Company were the primary facilitators in the publishing of this manual:

R. I. Schreck, Document Coordinator

E. A. Gordon, Technical Editor 


\section{DOE/RL-93-24-8}

This page intentionally left blank. 


\section{CONTENTS}

1.0 TANK CHARACTERIZATION DATA OVERVIEW

2.0 ACCESSING TANK CHARACTERIZATION DATA

3.0 TANK CHARACTERIZATION DATA TABLES

3.1 TANK FARM TABLE

3.2 WASTE TANK TABLE

3.3 TANK CORE TABLES

3.3.1 TANK CORE TABLE

3.3.2 TANK CORE SEGMENT TABLE

3.4 TANK SURFACE SAMPLE TABLE

3.5 TANK SUPERNATE SAMPLE TABLE

3.6 TCD SAMPLE TABLE

3.7 TCD ANALYSIS TABLES

3.7.1 TCD ANALYSIS TABLE

3.7.2 TCD ANALYSIS RESULT TABLE

3.7.3 TCD ANALYSIS RESULT CHANGE TABLE

3.8 WASTE TANK STATUS TABLE

3.9 SAMPLE RELATION TABLE

3.10 SAMPLE GROUP TABLES

3.10.1 SAMPLE GROUP TABLE

3.10.2 SAMPLE GROUP ELEMENT TABLE

3.11 TCD RESULT GROUP TABLES

3.11.1 TCD RESULT GROUP TABLE

3.11 .2 TCD RESULT GROUP ELEMENT TABLE

3.12 TANK INVENTORY TABLES

3.12.1 TANK INVENTORY SOURCE TABLE

3.12.2 INVENTORY SOURCE TYPE TABLE

3.12.3 TANK INVENTORY TABLE

3.12 .4 TANK INVENTORY UNCERTAINTY TABLE

3.12 .5 TANK INVENTORY CHANGE TABLE

3.12.6 TCD DOCUMENT REFERENCE TABLE

3.13 SAFETY CRITERIA TABLE

REFERENCES

APPENDIX A TCD DATA QUALIFIERS

APPENDIX B TCD DATA LOADING AND VERIFICATION PROCEDURES

APPENDIX C TCD SUPPORT PROGRAMS 
Section CONTENTS

Page 2 of 4

Date $04 / 15 / 94$
DOE/RL-93-24-8

\section{FIGURES}

1.0-1 Data Model Showing Relationships Among the Tank

Characterization Data Subject Area Tables and Their

Relationships with Tables Located in Other HEIS Subject Areas

2.0-1 TCD Menu

2.0-2 TCD Tank Data Menu

2.0-3 Tank Inventory Data Menu

2.0-4 Map of TCD Entry Points

3.1-1 Tank Farm Form

3.2-1 Waste Tank Form

3.3.1-1 Tank Core and Segment Form

3.3.2-1 Tank Core and Segment Form

3.4-1. Tank Surface Sample Form

3.5-1 Tank Supernate Sample Form

3.6-1 TCD Sample Form

3.7.1-1 TCD Analysis Form

3.7.2-1 TCD Analysis Result Form

3.7.3-1 TCD Analysis Result Change Form

3.8-1 Waste Tank Status Form

3.9-1 Sample Relation Form

3.10.1-1 Sample Group Form

3.10.2-1 Sample Group Element Form

3.11.1-1 TCD Result Group Form

3.11.2-1 TCD ResuTt Group Element Form

3.12.1-1 Tank Inventory Source Form

3.12.2-1 Inventory Source Type Form

3.12.3-1 Tank Inventory and Uncertainty Form 


\section{FIGURES (continued)}

3.12.4-1 Tank Inventory and Uncertainty Form

3.12.5-1 Tank Inventory Change View Form

3.12.6-1 TCD Document Reference Form

3.13-1 Safety Criteria Form 


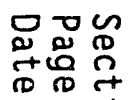

용요

붕욜

은

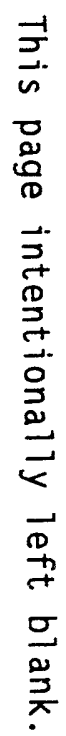

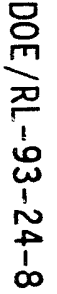




\section{THE TANK CHARACTERIZATION DATA SUBJECT AREA}

\subsection{TANK CHARACTERIZATION DATA OVERVIEW}

PURPOSE

\section{SCOPE}

Data Sources
The purpose of the Tank Characterization Data subject area of the Hanford Environmental Information System (HEIS) is to manage data acquired from waste tank characterization efforts. Tank samples provide a major portion of the data stored in this subject area. Also included are data from tank inventories that are analyzed to determine disposal requirements, such as suitability for grout or vitrification. The data provide the basis for developing safety analyses and closure plans, and for establishing and verifying compliance with waste acceptance specifications.

Four major sources of data make up the Tank Characterization Data subject area.

- Data from single-shell and double-shell tank core samples -- Core sampling analytical results include physical properties, radionuclides, major chemicals, and hazardous components. Waste analyses from single-shell tank cores provide data to support a supplemental environmental impact study (EIS) as well as provide data for disposal technology development and closure plans. Waste analyses from double-shell tank cores confirm waste designation(s) to satisfy State disposal permit application requirements and provide analytical acceptance criteria for storage and treatment of wastes.

- Data from waste tank surface samples -- Surface solids are removed from the waste tanks and analyzed to provide additional characterization of tank contents. The primary method for removing the surface samples is via auger sampling, although a few surface samples are obtained from sludge weight sampling or scraping debris from instruments removed from the tanks.

- Data from waste tank supernatant samples -Supernatant samples are used to verify process knowledge and confirm RCRA waste designation. Samples are collected from the appropriate double-shell tanks, characterized, and evaluated. 
Section

Page

Date
Data Types
$D O E / R L-93-24-8$

Laboratory characterization results are also used in design and safety analyses for pretreatment.

- Data from tank inventory estimates -- Estimates of tank inventories have been developed over the years based on a simulation programs, historical process knowledge, and evaluation of laboratory analyses of tank samples. These estimates are used to support tank safety and disposal analysis.

Four types of data are stored in the TCD subject area. Quali:iers for TCD analytical result data are listed in Appendix $A$. Data loading and verification procedures are described in Appendix B. Appendix C contains descriptions of the TCD programs available to authorized users to support data loading and maintenance.

- Description of the source of the samples -- This includes descriptions of the tanks farms and the waste tanks, and relevant periodic records concerning the status of a waste tank. These data are stored in the Tank Farm, Waste Tank, and Waste Tank Status tables.

- Data concerning the samples taken from the tanks -- Physical samples taken from waste tanks are described in the Tank Core, Tank Core Segment, Tank Surface Sample, and Tank Supernate Sample tables.

Physical samples are subsampled. Characteristics of the samples, both physical samples and subsamples, are stored in the TCD Sample table. The relationships between various samples (e.g., one sample may be a composite of a group of other samples) are stored in the Sample Relation table.

Samples may be grouped. Group contents and descriptions are stored in the Sample Group and Sample Group Element tables.

- Data concerning the chemical, radiological, or physical properties of TCD samples -- The samples are analyzed using a variety of protocols; most protocols have been developed specifically for the Hanford Site waste tanks. The results of all types of analyses are stored in the TCD Analysis and the TCD Analysis Result tables, with changes in the TCD Analysis Result Change table. 
Analytical results may be grouped. Group contents and descriptions are stored in the TCD Result Group and TCD Result Group Element tables.

- Data concerning calculated tank inventory based on analyses of sampling result data -- The data are stored in the Inventory Source Type, TCD Document Reference, Tank Inventory Source, Tank Inventory, Tank Inventory Change, Safety Criteria, and Tank Inventory Uncertainty tables.

DATA MODEL
Figure 1.0 - 1 is a data model showing associations among the TCD subject area tables and their relationships with other HEIS tables. The figure is a conceptual model; implementation details of the tables may differ slightly from what is presented in the diagram. The associations are described below. Capitalized items refer to both the actual item and the TCD table in which data about that item are stored.

- Each Tank Farm contains many waste tanks; each Waste Tank can have many cores removed for analysis. Each Tank Core is composed of a series of Tank Core Segments; each segment is defined as a TCD Sample. Each Waste Tank can have many Tank Surface Samples removed for analysis. Each Waste Tank can also have many Tank Supernate Samples removed for analysis. Each tank can have many Waste Tank Status records, which describe the physical conditions of the tank on a specific date. Each tank can have many Tank Inventory Source records. A Tank Inventory Source record represents one description of the contents of the waste tank.

- Each Waste Tank sample is entered into TCD Sample table. Each of these samples may be subsampled prior to analysis, allowing the use of different sample preparation methods. These subsamples are also TCD Samples. To provide a representative sample for a large portion of a tank, many samples can be composited to produce another TCD Sample. The relationship between samples, subsamples, and composites is documented in the Sample Relation table.

- Each sample submitted for laboratory analysis can have multiple laboratory analyses run. Each such analysis is described as a TCD Analysis. The results from the analysis are stored as TCD 
Analysis Results. To provide a historical audit trail of the change(s) made to a TCD Analysis Result record a TCD Analysis Result Change record is generated for each such change.

- To aid users in managing the complicated sampling structure, each user can define Sample Groups and assign samples to groups in the Sample Group Element table. To aid in managing the complicated results structure, each user can define TCD Result Group and assign samples to groups in the TCD Result Group Element table.

- TCD Samples are also stored in the Sample table.

- The Tank Inventory Source table stores information about sources of tank inventory estimates. The TCD Document Reference table contains bibliographic information about the documents in which sets of inventory estimates are published. The inventories can come from one of several different Inventory Source Types. The overall estimates are based on statistical analyses and scientific judgment, using actual samples from the tank and historical data. The approaches and algorithms used for making inventory determinations vary with the Inventory Source Type. The inventory source bas is can be actual sampling data or extrapolated data based on $W$ at is considered to be a representative tank's inventory results. Constituent inventory estimates are stored in the Tank Inventory table. Each inventory estimate can have many statistical uncertainties calculated for it. These data are stored in the Tank Inventory Uncertainty table. To provide a historical audit trail of the change(s) made to a Tank Inventory record, a Tank Inventory Change record is generated for each such change.

Critical threshold values related to tank safety requirements are stored in the Safety Criteria table. 


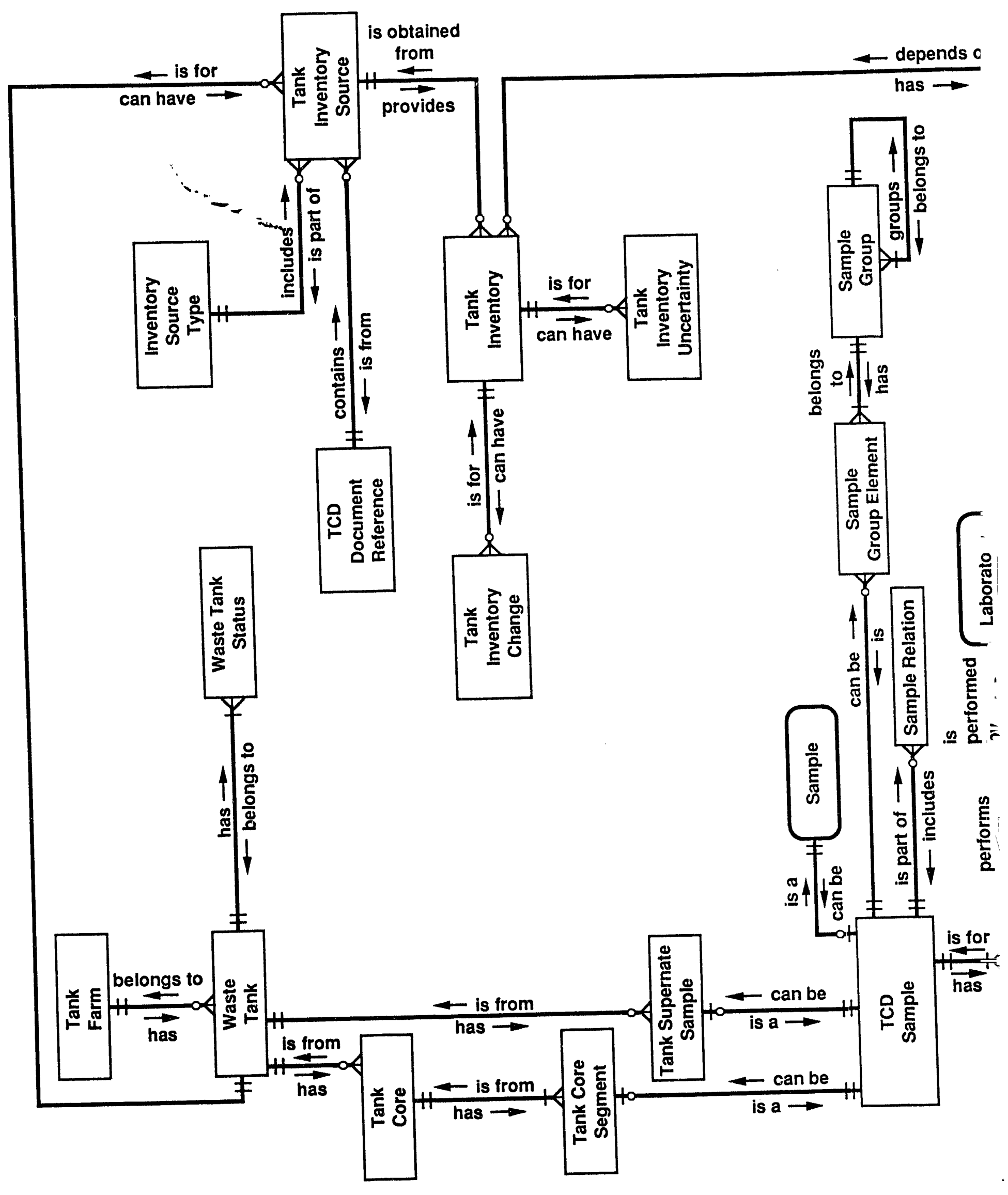




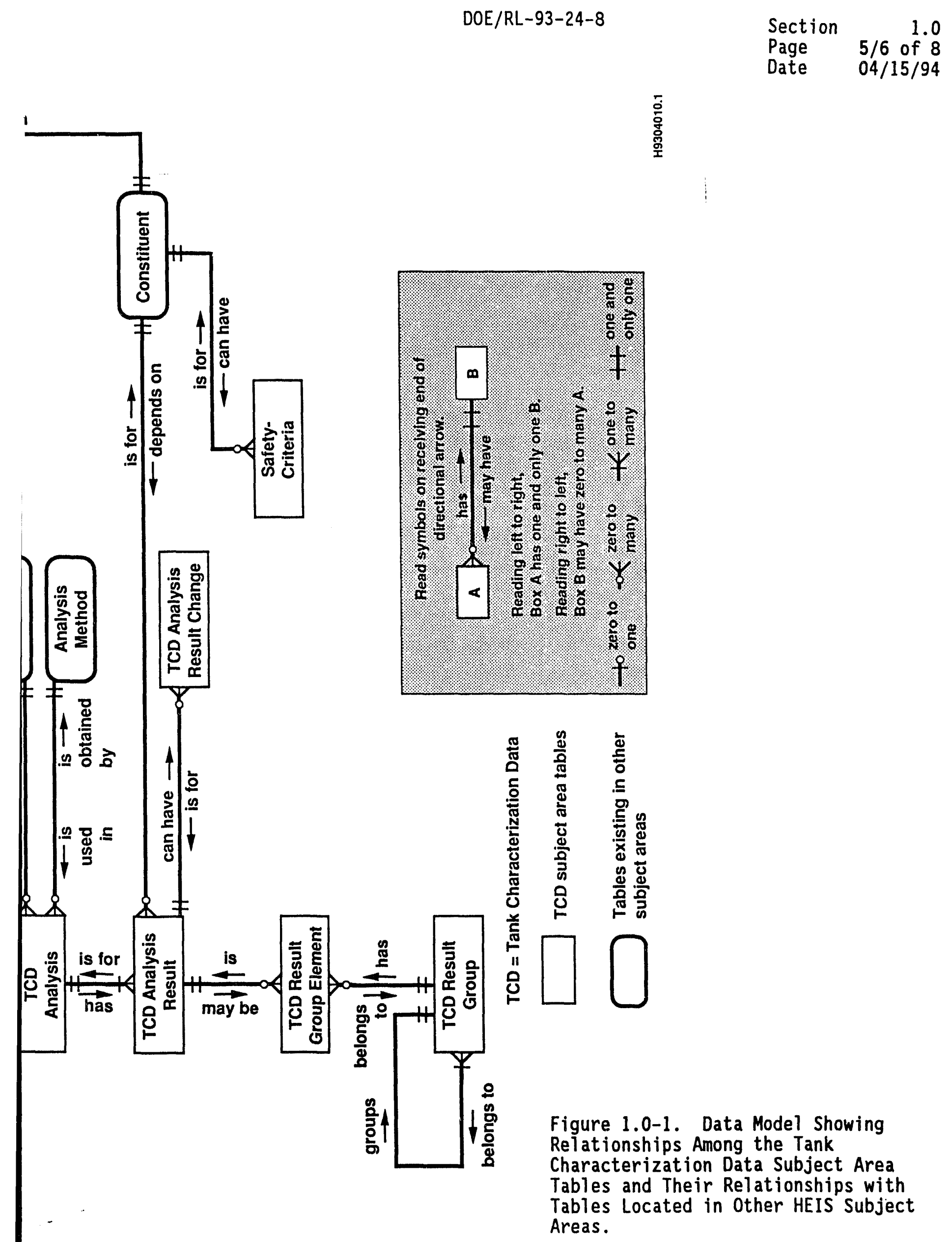


MENU SYSTEM

REPORTS

USERS
The TCD subject area allows you to navigate among the TCD forms using the HEIS query-by-form interface. Section 2.0 describes how to access the various TCD forms using this interface. The TCD tables are described in Section 3.0 .

Reporting information is provided in Section 4.0.

The users of the Tank Characterization Data subject area are (1) technical staff interested in waste tank data, (2) technical staff interested in levels of various chemical, radiological, and physical properties found when the samples are analyzed for the presence of various constituents, (3) data processing staff responsible for inserting and maintaining the data, (4) developers of disposal technologies, and (5) technical staff at regulatory agencies interested in monitoring the levels of various constituents found in the samples. 


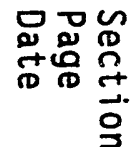

$$
\begin{aligned}
& \stackrel{8}{+\infty} \\
& \text { ज़유 }
\end{aligned}
$$

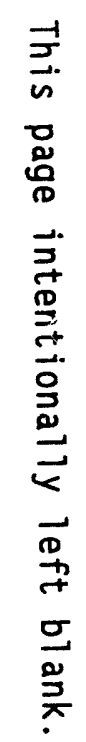




\subsection{ACCESSING TANK CHARACTERIZATION DATA}

INTRODUCTION
The TCD menus, presented in Figures $2 \cdot 0-1$ and 2.0-2, and 2.0-3 show all the entry points into the TCD forms. Figure 2.0-4 is a diagram of how these forms and other forms accessible from the menu options are connected. See Section 5.3 of the HEIS User's Guide (DOE-RL 1994a) for a detailed description of entry point maps. Section 3.0 describes each of the tables and forms associated with individual entry points.

- The TCD Tank Data Menu is a collection of entry points that provide access to data about waste tanks, samples from tanks, and the analys is and result data reported by the analytical laboratories.

- The Sample Group and Sample Group Element entries allow the creation of user-defined groups of samples for convenience in accessing tank data.

Currently you may establish groupings, but none of the data access software make use of these user-defined groupings. This facility will be added in the future. The linkage between this facility and the access of data will be driven by user needs.

- The TCD Result Group and Result Group Element entry points allow the creation of user-defined groups of TCD result records for convenience in accessing the tank data.

Currently you may establish groupings, but none of the data access software make use of these user-defined groupings. This facility will be added in the future. The linkage between this facility and the access of data will be driven by user needs.

- The Tank Inventory Data Menu is a collection of entry points that provide access to data about estimated tank inventories, their sources and uncertainties, as well as safety criteria associated with tank inventories. 
Section

Page

Date
2.0

2. of 4

$04 / 15 / 94$

Figure 2.0-1. TCD Menu.

HANFORD ENVIRONMENTAL INFORMATION SYSTEM Tank Characterization Data MENU-OPTIONS

TCD Tank Data Menu

Sample Group

TCD Result Group
Tank Inventory Data Menu Sample Group Element

TCD Result Group El ement

MOVE: Press [NEXT RECORD], [PREV RECORD], Or Arrow KeYs SELECT: Press [ACCEPT] (Browser), [DETAIL]' (Max Privilege) EXIT: Press [QUIT]

Figure 2.0-2. TCD Tank Data Menu.

HANFORD ENVIRONMENTAL INFORMATION SYSTEM

TCD Tank Data Menu

MENU-OPTIONS

Waste Tank

Tank Supernate Sample

Waste Tank Status

TCD Semple

TCD Analysis

TCD Analysis Result Change
Tank Core and Segment

Tank Surface Sample

Tank Farm

Semple Relation

TCD Analysis Result

TCD Result Change Reason Upd 
Figure 2.0-3. Tank Inventory Data Menu. HANFORD ENVIRONMENTAL INFORMATION SYSTEM Tank Inventory Data Menu

Tank Inventory Source

Tank Inventory and Uncertainty

Tank Inventory Change Update

Safety Criteria
Inventory Source Type

Tank Inventory Change view

TCD Document Reference

MOVE: Press [NEXT RECORD], [PREV RECORD], or Arrow KeYs

SELECT: Press [ACCEPT] (Browser), [DETAIL]' (Max Privilege) 

Section
2.0
$D O E / R L-93-24-8$
Date $04 / 15 / 94$

Figure 2.0-4. Map of TCD Entry Points.

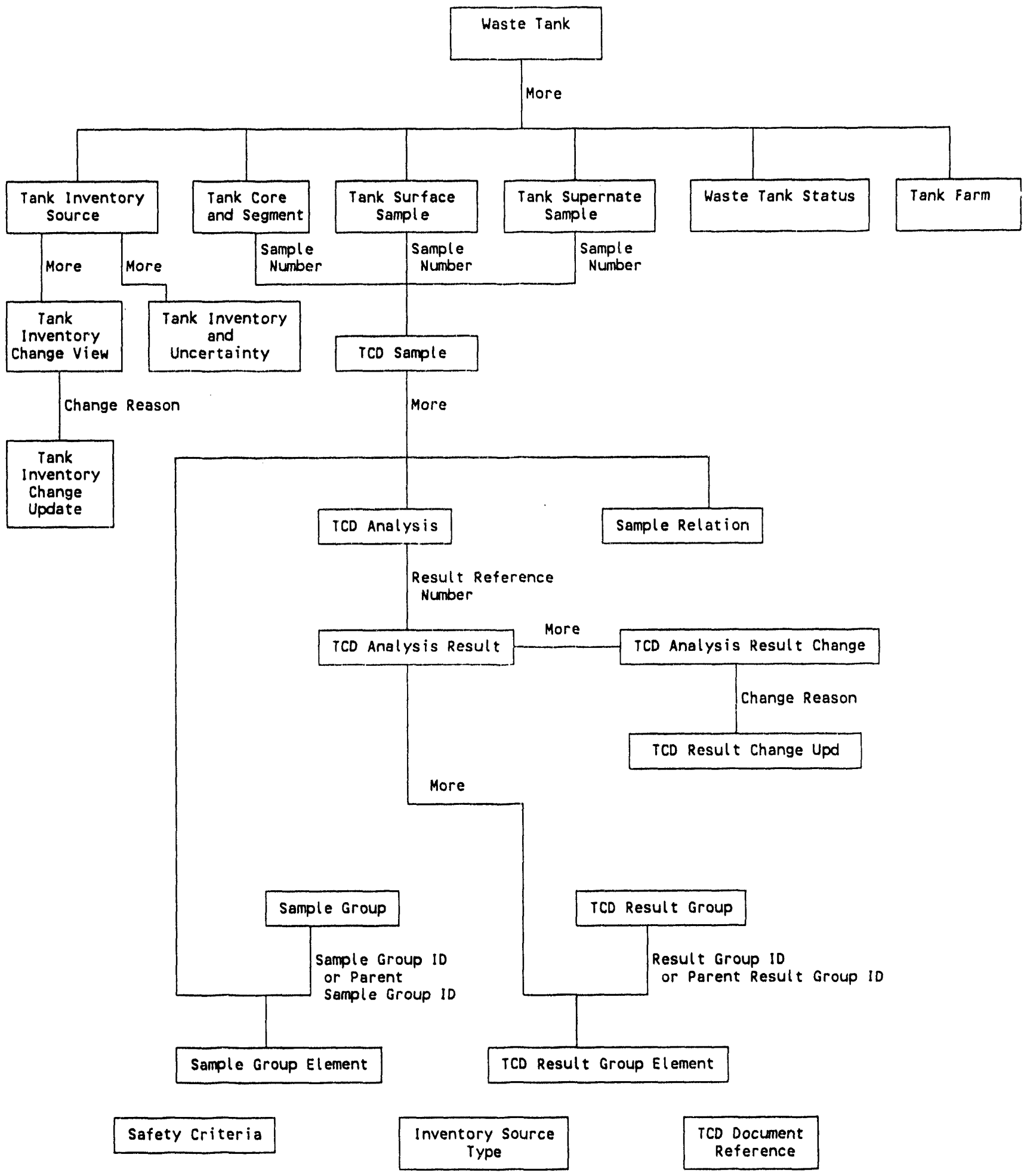




\subsection{TANK CHARACTERIZATION DATA TABLES}

NOTE: All TCD tables and forms contain both the Owner ID (owner id) and Access Level (access_level) fields. These àre required fields but not uñique identifiers for any particular record. Neither field is listed in the text tables for the sections that follow.

\subsection{TANK FARM TABLE}

(HEIS Database Table Name: tank_farm)

INTRODUCTION

SOURCE

\section{REQUIREMENTS}

Dependencies

None.

Special Processing None.

Code Lookup/

Validation

None.
The Tank Farm table contains descriptive data about physically and logically grouped sets of Hanford Site waste tanks, called tank farms. The Tank Farm ID is part of the tank or vault identification. For example, $A Q-101$ is a tank $I D$, with $A Q$ being the Tank Farm ID. The Tank Farm form is shown in Figure 3.1-1.

Figure 3.1-1. Tank Farm Form.

\begin{tabular}{|ll|}
\hline TANK FARM 10 & Tank Farm \\
Description & Name \\
Comment & \\
OWNER 10 & ACCESS LEVEL - \\
\hline
\end{tabular}

Data for this table come from the monthly Tarik Farm Surveillance and Waste Status Report (WHC 1988). 
Section

Page

Date

3.1

2 of 2

$01 / 14 / 94$

DOE/RL-93-24-8

Required Fields

Recommended Query

Fields

FORM FIELD NAMES/ DATABASE FIELD NAMES
Tank Farm ID*

Choice 1 - Tank Farm ID

Form field Nane

Comment

Description

Neme

Tank Farm ID
Database Field Name

tank_farm_comment

tank_farm_desc

tank farm_name

tank_farm_id 


\subsection{WASTE TANK TABLE}

INTRODUCTION

The Waste Tank table contains descriptive information about a particular tank. The table includes the tank ID, data on the dimensions and capacity of the tank, the tank type, and when it was constructed. The Waste Tank form is shown in Figure 3.2-1.

Figure 3.2-1. Waste Tank Form.

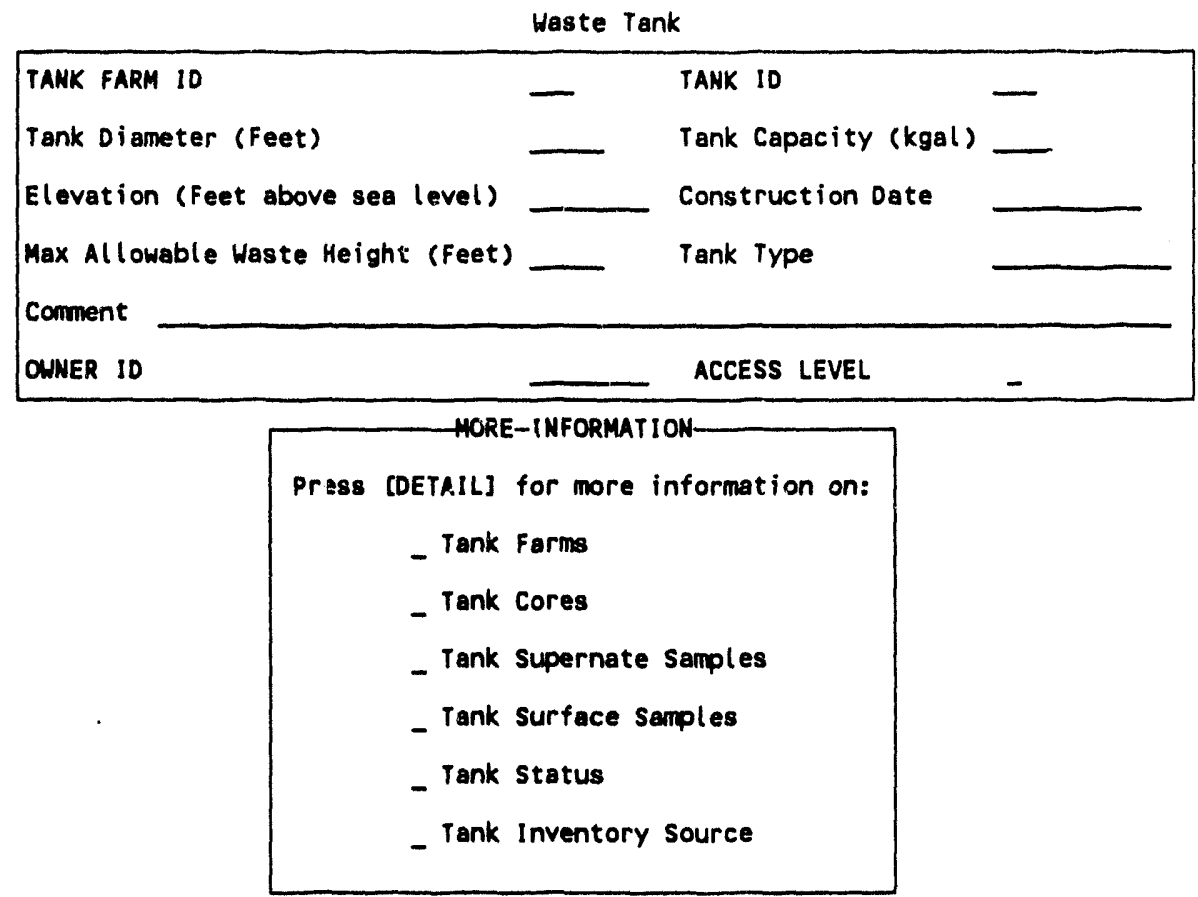

SOURCE

Data for this table come from the monthly Tank Farm Surveillance and Waste Status Report (WHC 1988).

\section{REQUIREMENTS}

Dependencies

Tank Farm ID must exist in the Tank Farm table.

Special Processing None.

Code Lookup/

Validation

Tank Farm ID Tank Type 


$\begin{array}{lr}\begin{array}{l}\text { Section } \\ \text { Page } \\ \text { Date }\end{array} \quad \begin{array}{r}3.2 \\ \text { of } 2\end{array} & \text { DOE/RL-93-24-8 } \\ 04 / 15 / 94 & \\ \text { Required Fields } & \begin{array}{l}\text { Tank Farm ID* } \\ \text { Tank ID* }\end{array} \\ \begin{array}{l}\text { Recommended Query } \\ \text { Fields }\end{array} & \text { Choice 1 - Tank Farm ID } \\ \text { Tank ID }\end{array}$

\section{FORM FIELD NAMES/ DATABASE FIELD NAMES}

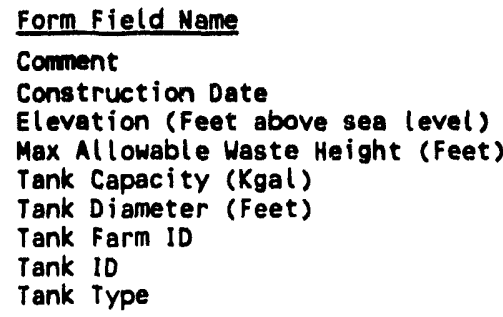

Tank Type

Database field Name

tank_comment

construction date

tank_elevation

max_äl lowable_waste_height

$\tan \bar{k}$ capacity

tank diameter

tank_farm_id

tank id

tank_type 


\subsection{TANK CORE TABLES}

\subsubsection{TANK CORE TABLE}

(HEIS Database Table Name: tank_core)

INTRODUCTION

SOURCE

\section{REQUIREMENTS}

Dependencies

Special Processing
The Tank Core table contains data about the sampling process that generated a set of core segments. Included in the table are the tank core ID, serial number, sample device type, riser ID, and the dates when sampling began and ended. The Tank Core tab1e is the upper half of the form shown in Figure 3.3.1-1. The tank core segment portion of the form is described in Section 3.3.2.

Figure 3.3.1-1. Tank Core and Segment Form.

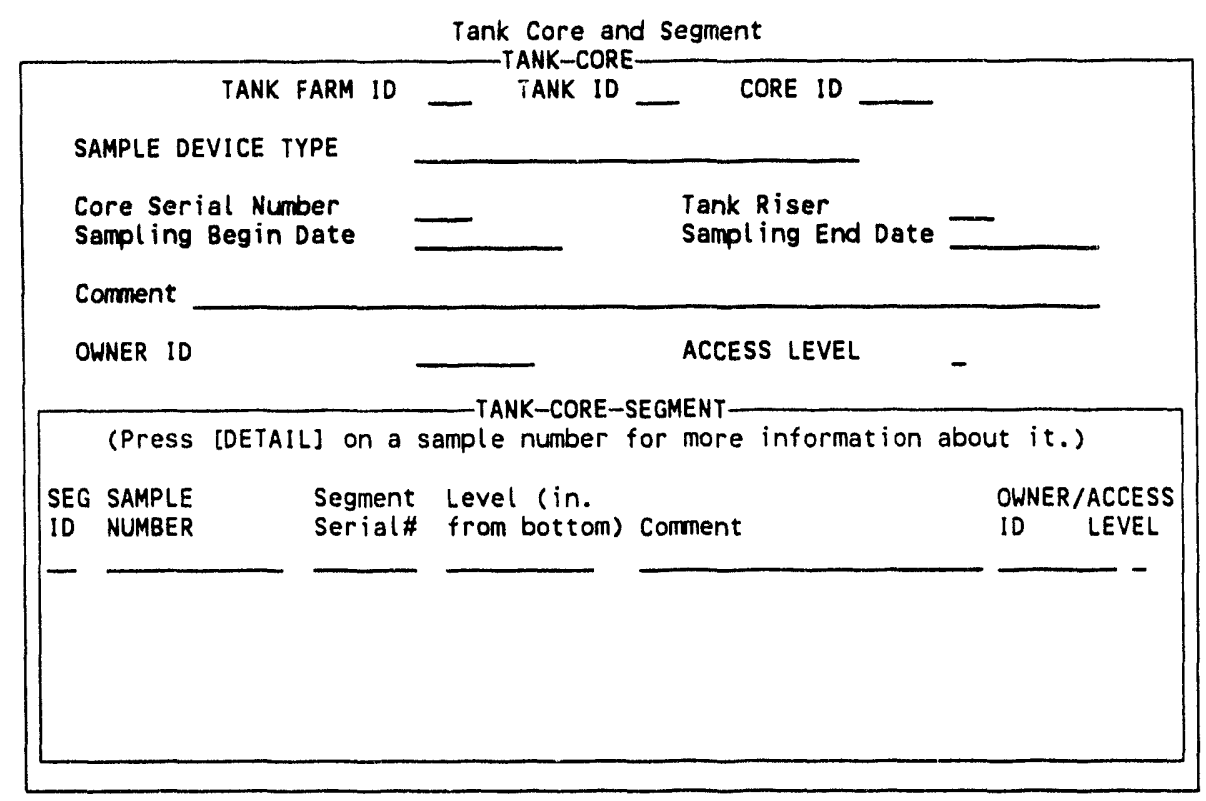

The analytical laboratory provides the data for this table.

The combination of Tank Farm ID and Tank ID must exist in the Waste Tank table.

None. 


\begin{tabular}{|c|c|}
\hline $\begin{array}{lr}\text { Section } & 3.3 .1 \\
\text { Page } & 2 \text { of } 2 \\
\text { Date } & 04 / 15 / 94\end{array}$ & $D O E / R L-93-24-8$ \\
\hline $\begin{array}{l}\text { Code Lookup/ } \\
\text { Validation }\end{array}$ & $\begin{array}{l}\text { Tank Farm ID } \\
\text { Sample Device Type }\end{array}$ \\
\hline Required Fields & $\begin{array}{l}\text { Core ID* } \\
\text { Tank Farm ID* } \\
\text { Tank ID* } \\
\text { Sample Device Type }\end{array}$ \\
\hline $\begin{array}{l}\text { Recommended Query } \\
\text { Fields }\end{array}$ & $\begin{array}{c}\text { Choice } 1 \text { - Tank Farm ID } \\
\text { Tank ID } \\
\text { Core ID }\end{array}$ \\
\hline $\begin{array}{l}\text { FORM FIELD NAMES/ } \\
\text { DATABASE FIELD NAMES }\end{array}$ & $\begin{array}{l}\text { Form Field Name } \\
\text { Corment } \\
\text { Core ID } \\
\text { Core Serial Number } \\
\text { Sample Device Type } \\
\text { Sampl ing Begin Date } \\
\text { Sampl ing End Date } \\
\text { Tank Farm 10 } \\
\text { Tank ID } \\
\text { Tank Riser }\end{array}$ \\
\hline
\end{tabular}

Database Field Name

tank_core_comment

tank_core_id

tank core-serial num

samp device type

sampling_begin_date

sampl ing_end_däte

tank farm id

tank_id

tank_riser 


\subsubsection{TANK CORE SEGMENT TABLE}

(HEIS Database Table Name: tank_core_segment)

\section{INTRODUCTION}

SOURCE

REQUIREMENTS

Dependencies

Special Processing
The Tank Core Segment table contains data about tank core segments that have been sampled. Included in the table are the segment ID, the sample number, the segment serial number, and the level in the tank from which the sample was taken. The Tank Core Segment table is the lower half of the form shown in Figure 3.3.2-1. The Tank Core portion of the form is described in Section 3.3.1.

Figure 3.3.2-1. Tank Core and Segment Form.

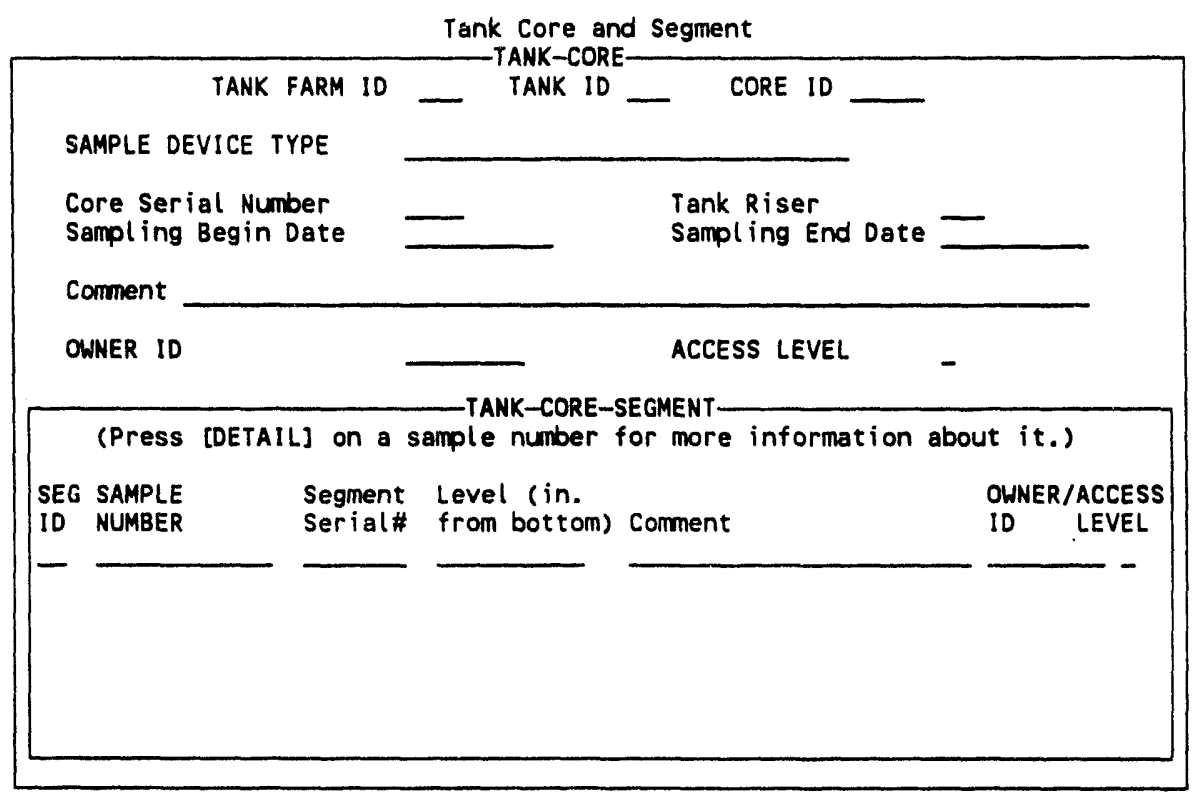

The analytical laboratory provides the data for this table.

The combination of Tank Farm ID, Tank ID, and Core ID must exist in the Tank Core table.

Sample Number must be previously generated or nonsystem generated (see Section 4.3.3 in the HEIS User's Guide [DOE-RL 1994a] for description). 
Section

Page

Date

3.3 .2

2 of 2

$04 / 15 / 94$

Code Lookup/

Validation

\section{Required Fields}

Recommended Query Fields

When a new record is stored, a corresponding entry in the TCD Sample table is created automatically for the new Sample Number.

Tank Farm ID

The Core ID, Tank Farm ID, and Tank ID fields are required but appear only in the Tank Core portion of the form.

Sample Number*

Core ID

Seg ID

Tank Farm ID*

Tank ID

Choice 1 - Tank Farm ID Tank ID

Core ID

Form Field Name

Corment

Level (in. from bottom)

Sample Number

Seg ID

Segment Serial \#

\section{Database Field Name}

tank core segment corment

tank_segment_leve $\bar{l}$

samp_num

tank_segment_id

tank_segment_serial_num 


\subsection{TANK SURFACE SAMPLE TABLE}

(HEIS Database Table Name: tank_surface_sample)

\section{INTRODUCTION}

SOURCE

\section{REQUIREMENTS}

Dependencies

Special Processing

Code Lookup/
Validation

Required Fields
The Tank Surface Sample table contains data about the sampling process that generated a sample of surface solids from a tank. Included in the table are the tank surface sample ID, sample device type, tank surface sample level, riser.ID, and the dates when sampling began and ended. The Tank Surface Sample table is shown in Figure 3.4-1.

Figure 3.4-1. Tank Surface Sample

Tank Surface Sample

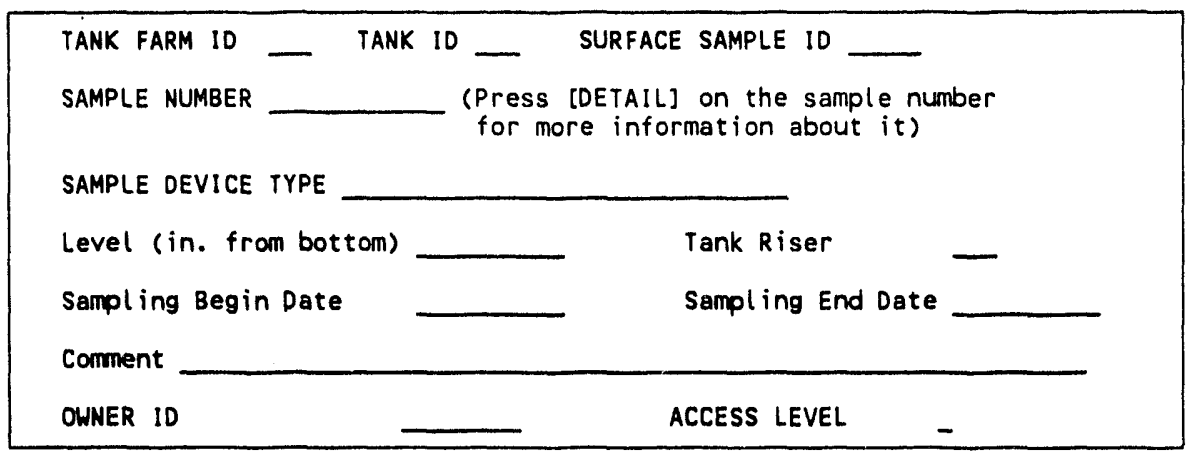

The analytical laboratory provides the data for this table.

The combination of Tank Farm ID and Tank ID must exist in the Waste Tank table.

Sample Number must be previously generated or nonsystem generated (see Section 4.3 .3 in the HEIS User's Guide [DOE-RL 1994a] for description).

When a new record is stored, a corresponding entry in the TCD Sample table is created automatically for the new Sample Number.

Samp Device Type

Tank Farm ID

Sample Device Type

Sample Number* 
Section

Page

3.4

2 of 2

Date $04 / 15 / 94$

Recommended Query Fields

FORM FIELD NAMES/ DATABASE FIELD NAMES
Tank Farm ID

Tank ID

Tank Surface Sample ID

Choice 1 - Sample Number

Choice 2 - Tank Farm ID

Tank ID

Core ID

Form field Name

Comment

Level

Sample Device Type

Sample Number

Sampl ing Begin Date

Sampl ing End Date

Surface Sample ID

Tank Farm ID

Tank ID

Tank Riser
Database Field Name

tank_surface_sample_comment

tank_surface_sample_level

samp_device_type

samp_num

sampling begin date

sampl ing end dàte

tank_surface_sample_id

tank_farm_id

tank_id

tank_riser 


\subsection{TANK SUPERNATE SAMPLE TABLE}

(HEIS Database Table Name: tank_supernate_sample)

INTRODUCTION

SOURCE

REQUIREMENTS

Dependencies

Special Processing

Code Lookup/ Validation
The Tank Supernate Sample table contains data about supernate samples taken directly from a waste tank. Information in the table includes the sample ID, level in the tank from which the sample was taken, the riser ID, and comments about the sample. The Tank Supernate Sample form is shown in Figure 3.5-1.

Figure 3.5-1. Tank Supernate Sample Form. Tank Supernate Sample

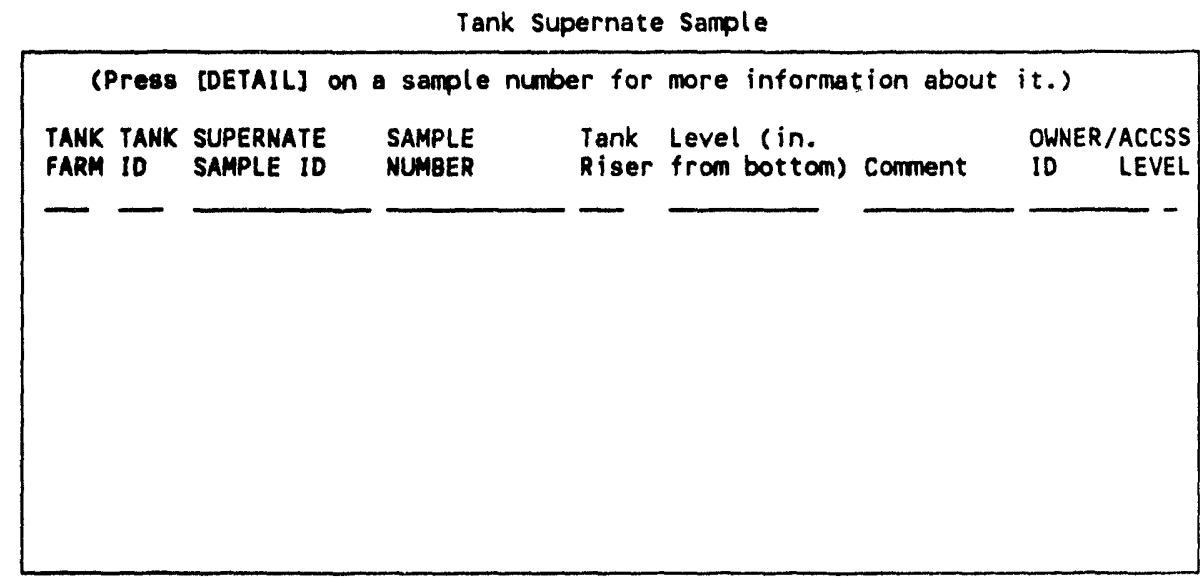

The analytical laboratory provides the data for this table.

The combination of Tank Farm and Tank ID must exist in the Waste Tank table.

Sample Number must be previously generated or nonsystem generated (see Section 4.3.3 in the HEIS User's Guide [DOE-RL 1994a] for description).

When a new record is stored, a corresponding entry in the TCD Sample table is created automatically for the new Sample Number.

Tank Farm 
Section

Page

3.5

Date 2 of 2 $04 / 15 / 94$

Required Fields

Recommended Query Fields DATABASE FIELD NAMES
Sample Number*

Supernate Sample ID

Tank Farm

Tank ID

Choice 1 - Sample Number

Choice 2 - Tank Farm

Tank ID

Supernate Sample ID

Form field Name

Conment

Level (in. from bottom)

Semple Number

Supernate Sample ID

Tank Farm

Tank ID

Tank Riser
Database field Name

tank_supernate_comment

tank_supernate level

samp_num

tank_supernate_sample_id

tank_farm id

tank id

tank_riser 


\subsection{TCD SAMPLE TABLE}

(HEIS Database Table Name: tcd_sample)

\section{INTRODUCTION}

The TCD Sample table contains data concerning samples taken from Hanford Site waste tanks or from waste processing points connected with the waste tanks. The TCD Sample form is shown in Figure 3.6-1.

The TCD Sample table relates each sample to one of the TCD sources. This table also adds further context for the sample, such as sample date and time, who did the sampling, the log book $I D$, and the page the sampling information is recorded on.

Figure 3.6-1. TCD Sample Form.

TCD Sample

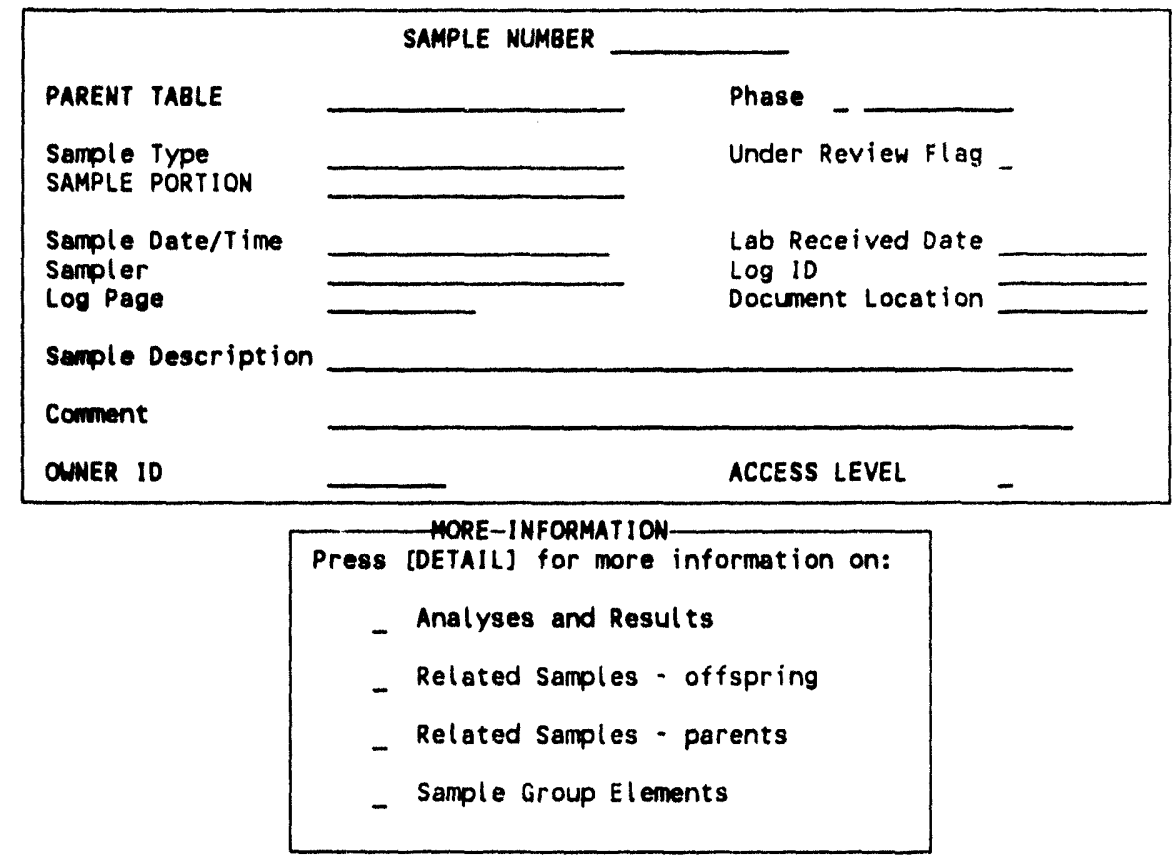

SOURCE

Data for this table are generated automatically by the system when Tank Core Segment and Tank Supernate Sample records are entered. Additional descriptive information can be entered by the data owner or laboratory, using the form shown in Figure 3.6-1.

Samples unrelated to Tank Core Segment or Tank Supernate Sample can be entered by the laboratory. 


\section{REQUIREMENTS}

Dependencies

Special Processing

Code Lookup/

Validation

Required Fields

Recommended Query Fields

FORM FIELD NAMES/ DATABASE FIELD NAMES

None.

Instructions for date restrictions are found in Section 4.3.4 of the HEIS User's Guide.

Sample Number must be previously generated or non-system generated (see Section 4.3.3 in the HEIS User's Guide [DOE-RL 1994a] for description). The associated Sample table record is generated or modified.

Parent Table

Phase

Sample Portion

Parent Table

Sample Number*

Choice 1 - Sample Number

\section{Form Field Name}

Comment

Document Location

Lab Received Date

$\log 10$

Log Page

Parent Table

Phase

Sample Date/Time

Sample Description

Semple Number

Semple Portion

Semple Type

Sempler

Under Review Flag

\section{Database Field Name}

samp_comment

doc-Toc

lab_received_date

$\log _{-}$id

log-page

parent_table

phase

samp_date_t ime

samp_desc

samp_num

samp_portion

samp type

sampler

under_review_flag 


\subsubsection{TCD ANALYSIS RESULT TABLE}

(HEIS Database Table Name: tcd_analysis_result)

\section{INTRODUCTION}

The TCD Analysis Result table contains the actual quantitative values obtained from a sample for a constituent, analyte, and/or property via a particular analytical method. The table includes data related to the result, such as result qualifiers and an uncertainty value. The TCD Analysis Result form is shown in Figure 3.6.2-1.

Figure 3.6.2-1. TCD Analysis Result Form. TCO Analysis Result

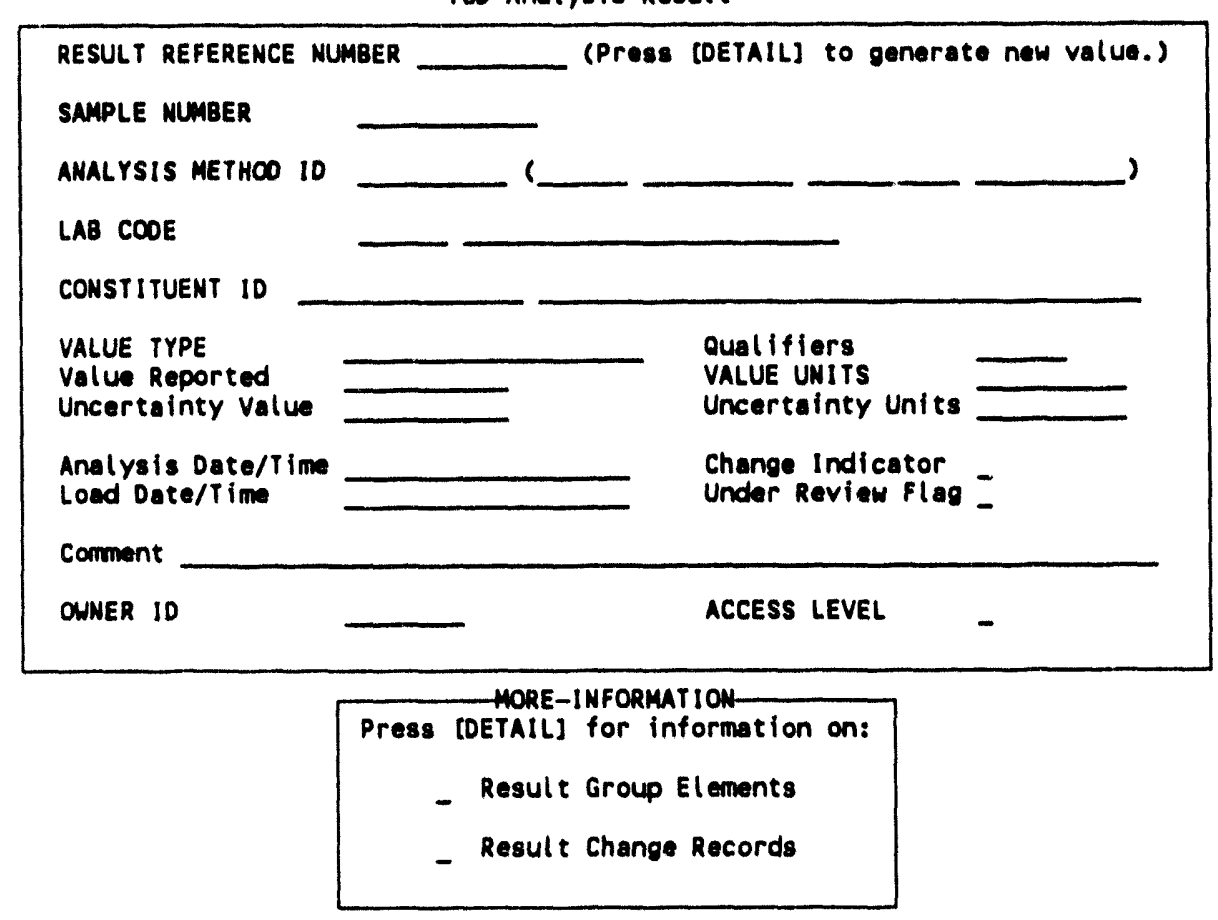

SOURCE

The analytical laboratory provides the data for this table.

\section{REQUIREMENTS}

Dependencies

The combination of Analys is Method ID, Lab Code, and Sample Number must exist in the TCD Analysis table.

Constituent ID must exist in the Constituent table. 


\begin{tabular}{|c|c|}
\hline $\begin{array}{lr}\text { Section } & 3.6 .2 \\
\text { Page } & 2 \text { of } 4 \\
\text { Date } & 01 / 14 / 94\end{array}$ & $D O E / R L-93-24-8$ \\
\hline Special Processing & $\begin{array}{l}\text { Change Indicator is system generated. } \\
\text { Change Indicator may not be queried from this form. } \\
\text { Load Date is system generated. } \\
\text { Instructions for the following are found in } \\
\text { Section } 4.3 .4 \text { of the HEIS User's Guide: } \\
\text { - Date restrictions } \\
\text { - Fields displayed in scientific notation. }\end{array}$ \\
\hline $\begin{array}{l}\text { Code Lookup/ } \\
\text { Validation }\end{array}$ & $\begin{array}{l}\text { Analysis Method ID } \\
\text { Constituent ID } \\
\text { Lab Code } \\
\text { Uncertainty Units } \\
\text { Value Type } \\
\text { Value Units }\end{array}$ \\
\hline Required Fields & $\begin{array}{l}\text { Analysis Method ID } \\
\text { Const ituent ID } \\
\text { Lab Code } \\
\text { Result Reference Number* } \\
\text { Sample Number } \\
\text { Value Type } \\
\text { Value Units }\end{array}$ \\
\hline $\begin{array}{l}\text { Recommended Query } \\
\text { Fields }\end{array}$ & $\begin{aligned} \text { Choice } 1 \text { - } & \text { Result Reference Number } \\
\text { Choice } 2 \text { - } & \text { Sample Number } \\
& \text { Analysis Method ID } \\
& \text { Lab Code } \\
& \text { Constituent ID }\end{aligned}$ \\
\hline
\end{tabular}


Section

Page

Date

Form field Name

Change Indicator
Database Field Name

analysis_date_time

anal_mthd_id

change_indicator

anal comment

con Td

lab_code

lood_date

ted result qualifiers

rrn

somp_num

uncertainty value

under_roview_flag

volue rpte

value_units

value_type uncortainty units
3.6 .2

3 of 4

$01 / 14 / 94$
Analysis Date/Time

Analysis Method IO

Comment

Constituent 10

Lab code

Load Date/T im

Qualifiera

Result Reforence Mumber

Semple Number

Uncertainty Units

Uncertointy Value

Under Review Flag

Value Reported

Value Units

value Type

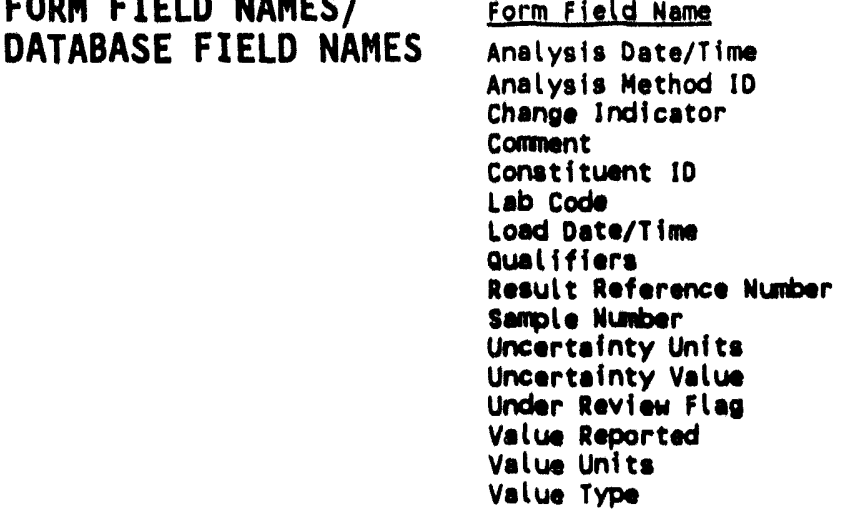



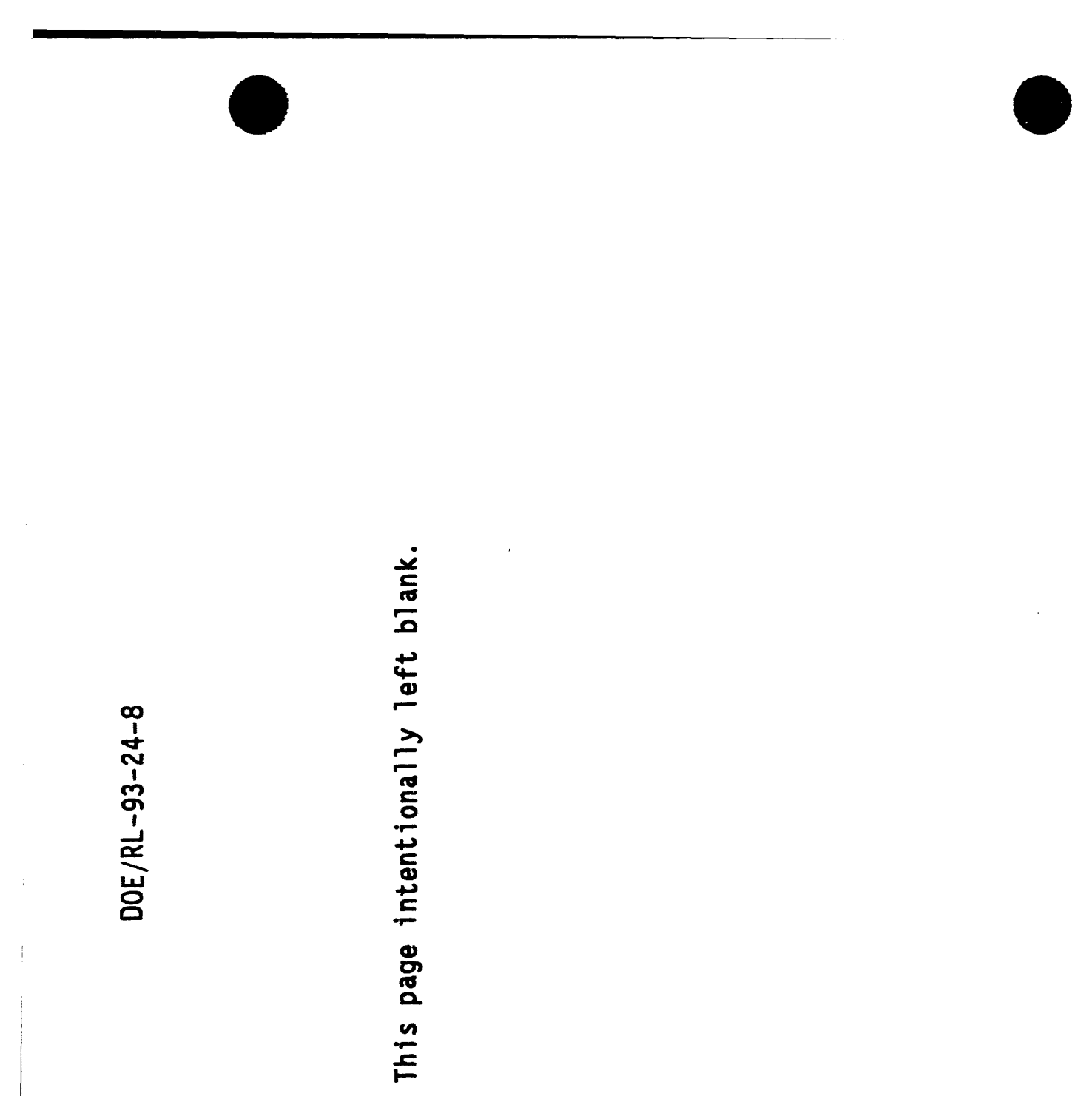

它导

등

芒哭兽

ฝัฐ 


\subsubsection{TCD ANALYSIS RESULT CHANGE TABLE}

(HEIS Database Table Name: tcd_analysis_result_change)

\section{INTRODUCTION}

SOURCE

REQUIREMENTS
The TCD Analysis Result Change table contains a timestamped historical record of changes made to tank characterization analys is result records. Some aspects of the results, such as value reported and qualifiers, are subject to change. The reason for the change, the change authority and user name, the change code, and the date/time of change also are stored. The TCD Analysis Result Change View form shown in Figure 3.6.3-1 provides a way to view this historical record. To access this form, choose the "TCD Result Change" option on the TCD Tank Data menu.

Figure 3.6.3-1. TCD Analys is Result Change Form. TCD Analysis Result Change

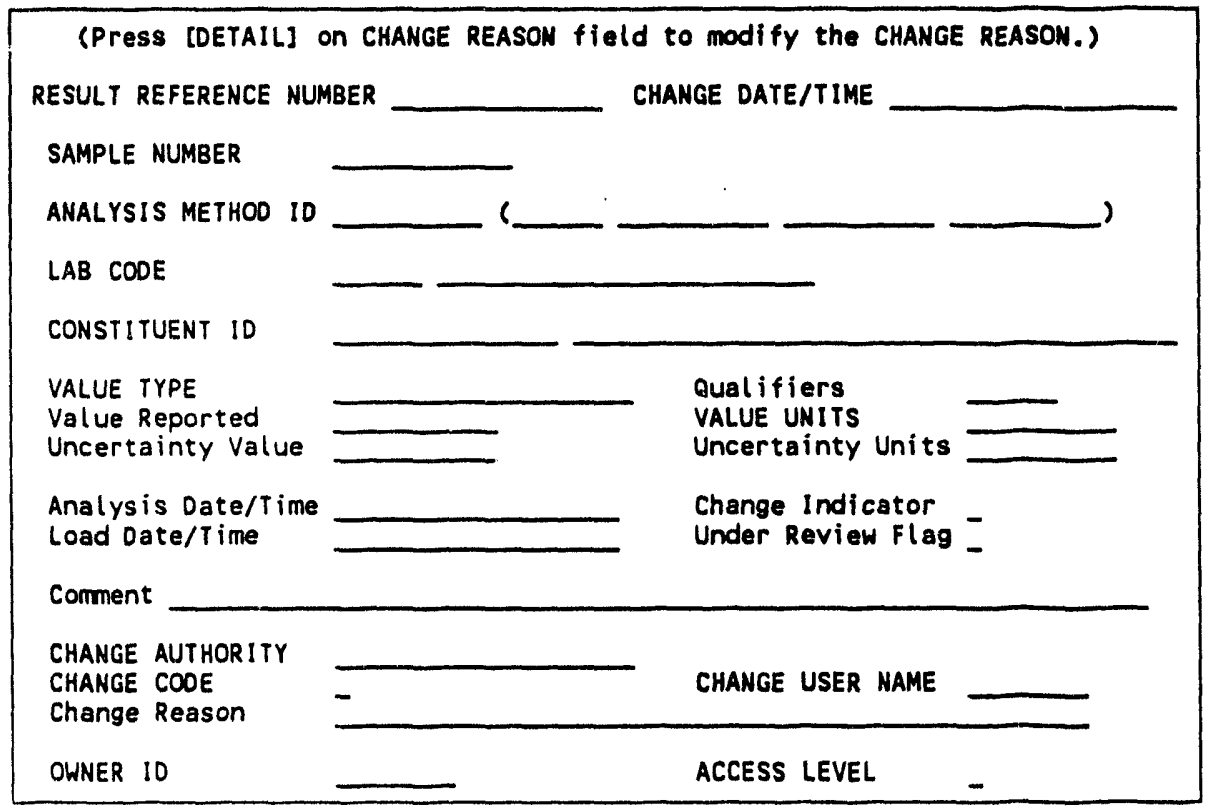

The source of the data is a previous record in the TCD Analys is Result table. These records are generated automatically when a result record is modified or deleted. See Section 4.3.5 of the HEIS User's Guide (DOE-RL 1994a) for details.

"Dependencies" and "Special Processing" are the same as found in the TCD Analysis Result table (see Section 3.6.1). The "Required Fields," "Code 
Section

Page

3.6 .3

2 of 2

Date
Code Lookup/
Validation

Required Fields

Recommended Query Fields

Lookup/Validation," and "Form Field Name/Database

Field Name" lists are the same with the exception of specific changes listed in the sections below. A complete description of the change record generation process is found in Section 4.3.5 of the HEIS User's Guide.

All fields in the TCD Analysis Result table plus -

Change Code

Change Reason

All fields in the TCD Analysis Result table plus -

Change Authority

Change Code

Change Reason

Change User Name

Choice 1 - Result Reference Number Change Date/Time

Choice 2 - Sample Number Analys is Method ID Lab Code Constituent ID

FORM FIELD NAMES/ DATABASE FIELD NAMES
All fields in the TCD Analysis Result table plus -

Form Field Name

Change Authority

Change Code

Change Date/Time

Change Reason

Change User Name
Database Field Name

change_authority

change code

change_date_time

change_reason

change_user_name 


\subsection{TCD ANALYSIS TABLES}

\subsubsection{TCD ANALYSIS TABLE \\ (HEIS Database Table Name: tcd_analysis)}

INTRODUCTION

SOURCE
The TCD Analysis table contains data about the analytical process. Included in the table are the name of the person performing the analysis, the date and time of the sample preparation, lab sample identification, the sample preparation type (method), and the dilution factor (if any). The TCD Analysis table is in the upper half of the form shown in Figure 3.7.1-1. The lower half shows the TCD analysis results associated with the TCD Analysis.

Figure 3.7.1-1. TCD Analys is Form.

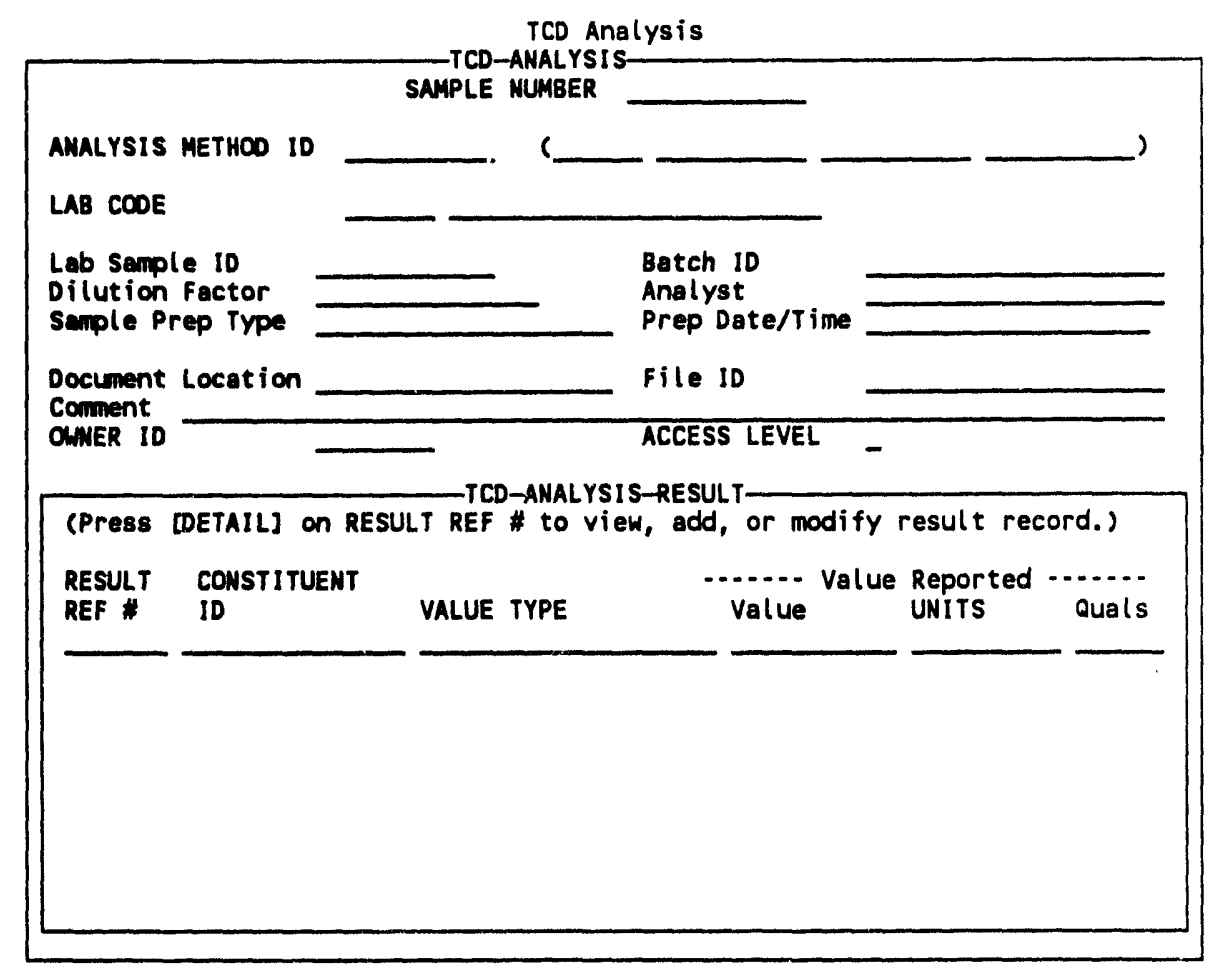

The analytical laboratory provides the data for this table. 
Section

Page 3.7 .1

Date

DOE/RL-93-24-8

\section{REQUIREMENTS}

Dependencies

Analysis Method ID must exist in the Analysis Method table.

Lab Code must exist in the Laboratory table.

Sample Number must exist in TCD Sample table.

Special Processing None.

Code Lookup/

Validation

Required Fields

Recommended Query Fields

FORM FIELD NAMES/ DATABASE FIELD NAMES
Analysis Method ID

Lab Code

Analysis Method ID*

Lab Code*

Sample Number*

\section{Choice 1 - Sample Number Analysis Method ID Sample Number}

Database Field Nane

anal_mthd_id

analyst

batch_id

analys is_comment

dilut_factor

doc_loc

file id

lab_code

lab_samp_id

samp_prep_date_time

samp_num

samp_prep_type 


\subsubsection{TCD ANALYSIS RESULT TABLE}

(HEIS Database Table Name: tcd_analysis_result)

\section{INTRODUCTION}

SOURCE

\section{REQUIREMENTS}

Dependencies
The TCD Analysis Result table contains the actual quantitative values obtained from a sample for a constituent, analyte, and/or property via a particular analytical method. The table includes data related to the result, such as result qualifiers and an uncertainty value. The TCD Analys is Result form is shown in Figure 3.7.2-1.

Figure 3.7.2-1. TCD Analysis Result Form.

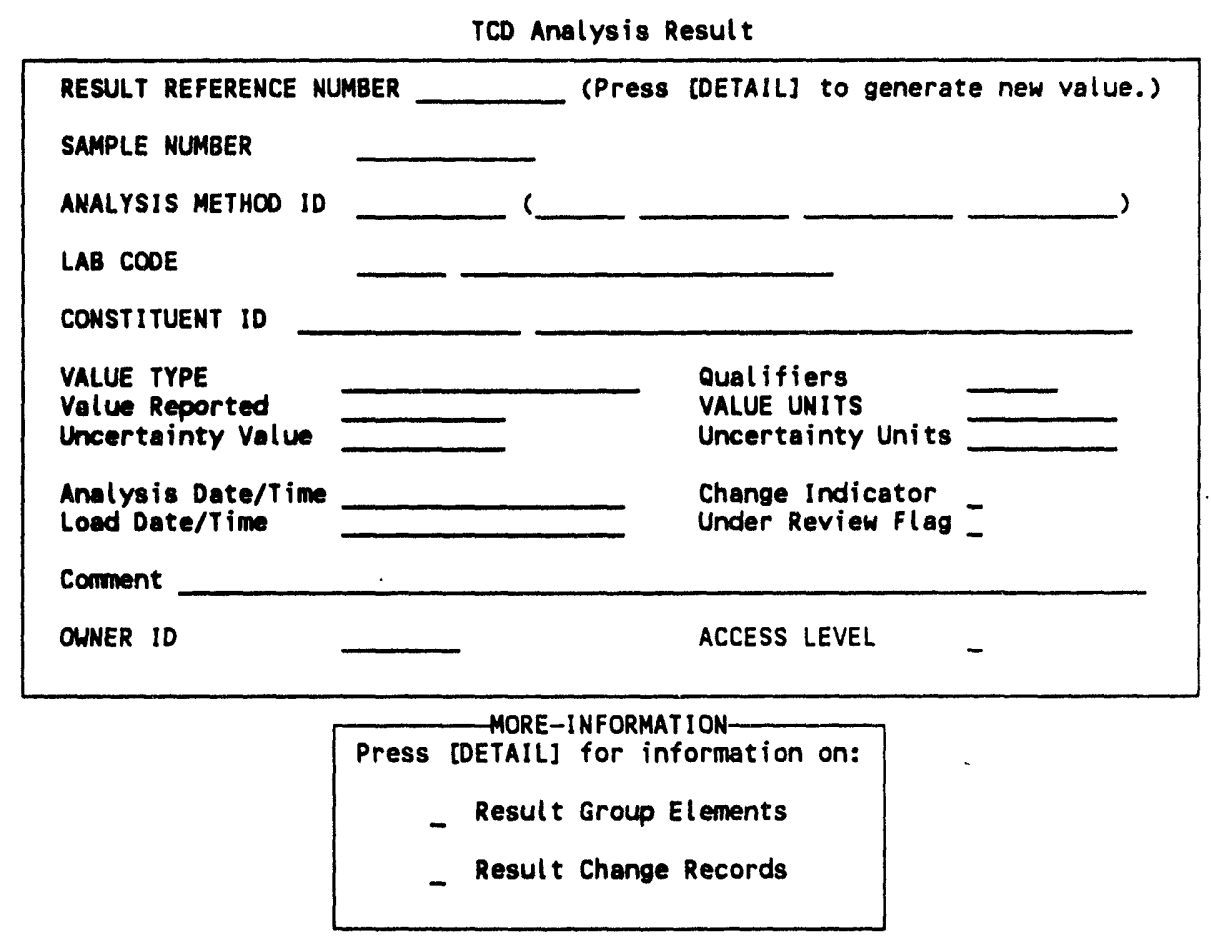

The analytical laboratory provides the data for this table.

The combination of Analys is Method ID, Lab Code, and Sample Number must exist in the TCD Analysis table.

Constituent ID must exist in the Constituent table. 


\begin{tabular}{|c|c|}
\hline $\begin{array}{lr}\text { Section } & 3.7 .2 \\
\text { Page } & 2 \text { of } 4 \\
\text { Date } & 04 / 15 / 94\end{array}$ & DOE/RL-93-24-8 \\
\hline Special Processing & $\begin{array}{l}\text { Change Indicator is system generated. } \\
\text { Change Indicator may not be queried from this form. } \\
\text { Load Date is system generated. } \\
\text { Instructions for the following are found in } \\
\text { Section } 4.3 .4 \text { of the HEIS User's Guide: } \\
\text { - Date restrictions } \\
\text { - Fields displayed in scientific notation } \\
\text { - The relationship between Form Number and Format } \\
\text { Type. }\end{array}$ \\
\hline $\begin{array}{l}\text { Code Lookup/ } \\
\text { Validation }\end{array}$ & $\begin{array}{l}\text { Analysis Method ID } \\
\text { Constituent ID } \\
\text { Lab Code } \\
\text { Uncertainty Units } \\
\text { Value Type } \\
\text { Value Units }\end{array}$ \\
\hline Required Fields & $\begin{array}{l}\text { Analysis Method ID } \\
\text { Constituent ID } \\
\text { Lab Code } \\
\text { Result Reference Number* } \\
\text { Sample Number } \\
\text { Value Type } \\
\text { Value Units }\end{array}$ \\
\hline $\begin{array}{l}\text { Recommended Query } \\
\text { Fields }\end{array}$ & $\begin{array}{c}\text { Choice } 1 \text { - Result Reference Number } \\
\text { Choice 2 - Sample Number } \\
\text { Analysis Method ID } \\
\text { Lab Code } \\
\text { Constituent ID }\end{array}$ \\
\hline
\end{tabular}


FORM FIELD NAMES/ DATABASE FIELD NAMES
Form Field Name

Analysis Date/Time Analysis Method ID

Change Indicator

Comnent

Constituent 10

Lab code

Load Date/Time

Qualifiers

Result Reference Number

Semple Number

Uncertainty Units

Uncertainty Value

Under Review $\mathrm{Flag}$

Value Reported

Value Units

Value Type
Database field Name

analys is_date_time

anal_mthd id

change_indicator

anal comment

con_id

lab code

load date

tcd_result_qualifiers

rrn

samp num

uncertainty_units

uncertainty value

under_review_flag

value rptd

value units

value_type 
Section

Page

Date

3.7 .2

4 of 4

$04 / 15 / 94$

DOE/RL-93-24-8

This page intentionally left blank. 


\subsubsection{TCD ANALYSIS RESULT CHANGE TABLE}

(HEIS Database Table Name: tcd_analysis_result_change)

\section{INTRODUCTION}

SOURCE

\section{REQUIREMENTS}

The TCD Analysis Result Change table contains a timestamped historical record of changes made to tank characterization analys is result records. Some aspects of the results, such as value reported and qualifiers, are subject to change. The reason for the change, the change authority and user name, the change code, and the date/time of change also are stored. The TCD Analysis Result Change View form shown in Figure 3.7.3-1 provides a way to view this historical record. To access this form, choose the "TCD Result Change" option on the TCD Tank Data menu.

Figure 3.7.3-1. TCD Analysis Result Change Form. TCD Analysis Result Change

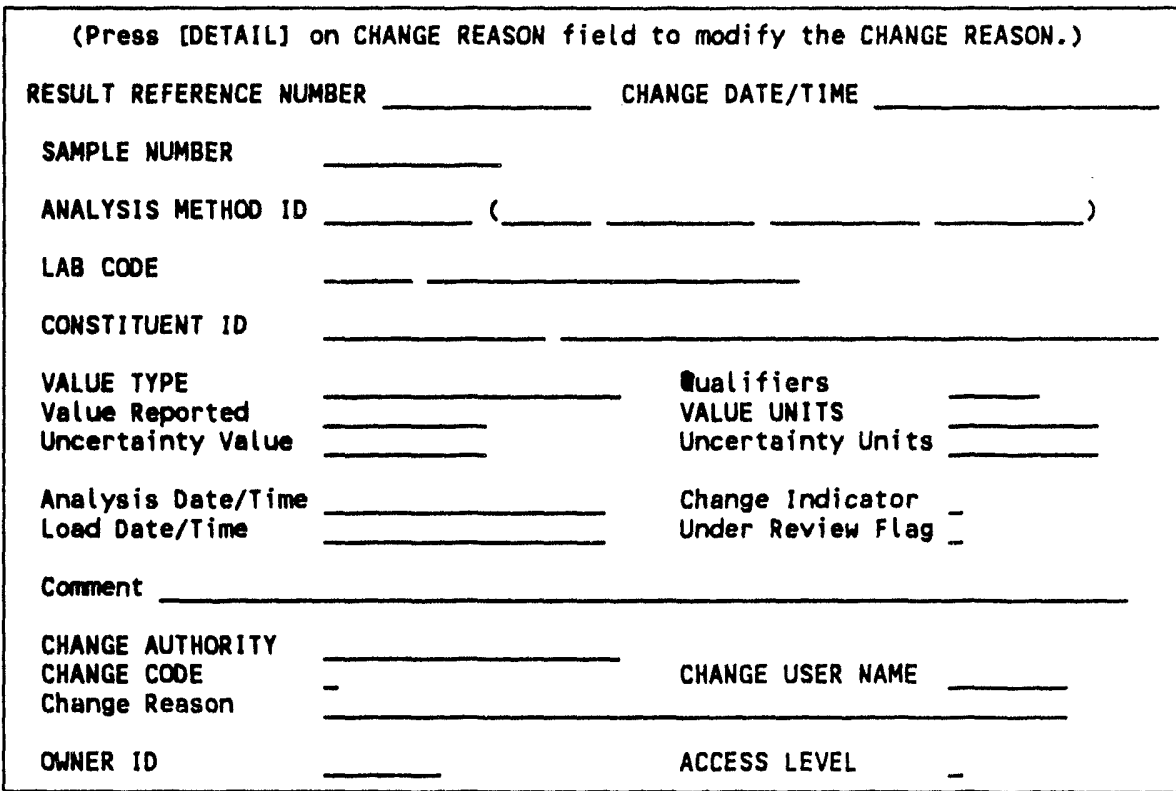

The source of the data is a previous record in the TCD Analysis Result table. These records are generated automatically when a result record is modified or deleted. See Section 4.3.5 of the HEIS User's Guide (DOE-RL 1994a) for details.

"Dependencies" and "Special Processing" are the same as found in the TCD Analysis Result table (see Section 3.7.1). The "Required Fields," "Code 


$\begin{array}{lr}\text { Section } & 3.7 .3 \\ \text { Page } & 2 \text { of } 2 \\ \text { Date } & 04 / 15 / 94\end{array}$

Code Lookup/

Validation

Required Fields

Recommended Query Fields

FORM FIELD NAMES/ DATABASE FIELD NAMES
Lookup/Validation," and "Form Field Name/Database Field Name" lists are the same with the exception of specific changes listed in the sections below. A complete description of the change record generation process is found in Section 4.3.5 of the HEIS User's Guide.

All fields in the TCD Analysis Result table plus -

Change Code

Change Reason

All fields in the TCD Analysis Result table plus -

Change Authority

Change Code

Change Reason

Change User Name

Choice 1 - Result Reference Number Change Date/Time

Choice 2 - Sample Number Analys is Method ID Lab Code

Constituent ID

All fields in the TCD Analysis Result table plus -
Database field Name

change_authority

change_code

change_date_time

change-reasón

change_user_name 


\subsection{WASTE TANK STATUS TABLE}

(HEIS Database Table Name: waste_tank_status)

\section{INTRODUCTION}

SOURCE

\section{REQUIREMENTS}

Dependencies
The Waste Tank Status table provides a way of retaining information related to tank observations that are not usually associated with samples and analyses. Included is dated information on the volume of various wastes and the methods used to obtain the volume data, the tank temperature and specific gravity, when the tank was stabilized, the tank integrity, and the date of the most recent tank photograph. The Waste Tank Status form is shown in Figure 3.8-1.

Figure 3.8-1. Waste Tank Status Form.

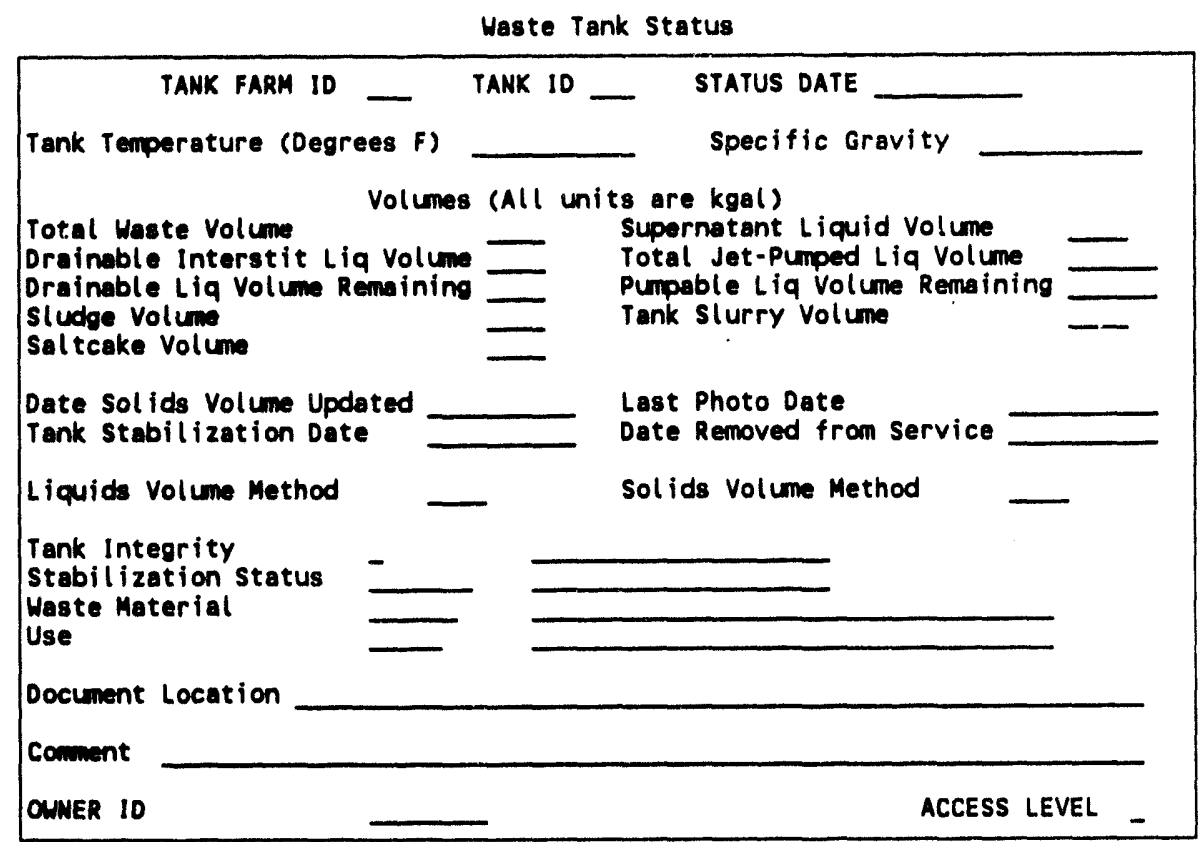

Data for this table come from the monthly Tank Farm Surveillance and Waste Status Report (WHC 1988).

The combination of Tank Farm ID and Tank ID must exist in the Waste Tank table. 
Section

Page

Date 3.8

2 of 2

$04 / 15 / 94$

Special Processing

Code Lookup/

Validation

Required Fields

Recommended Query

Fields

FORM FIELD NAMES/ DATABASE FIELD NAMES
None.

Stabilization Status

Tank Farm ID

Tank Integrity

Use

Waste Material

Status Date*

Tank Farm ID*

Tank ID*

\section{Choice I - Tank Farm ID Tank ID Status Date}

\section{Eorm Field Hame}

Comment

Date Removed from Service

Date Solid Volume Updated

Document Location

Drainable Interstit Liq Volume

Drainable Liq Volume Remaining

Last Photo Date

Liquids Volume Method

Pupable Liq Volume Remaining

Sal tcake Volume

sludge Volume

Solids Volume Method

Specific Gravity

Stabilization Status

Status Date

Supernatant Liquid Volume

Tank Farm 10

Tank 10

Tank Integrity

Tank slurry volume

Tank Stabilization Date

Tonk Temperature (Degrees F)

Total Jet-Pumped Liq Volume

Total Waste Volume

Use

Waste Material

\section{Database Field Nama}

waste_tank_status_comment

tank removed_from_service_date sol id̄s vol uné_updäte date

doc $10 \mathrm{c}$

drainable_interstitial liquol

drainable-lia vol remoining

last photo date

liquids_voTume_method

pumpable_liquoot_remaining

sal tcake_volume

sludge volume

sol ids_vol ume method

tank_specific_gravity

tank stabilization status

waste tank status date

superñatant liquid_volume

tank_farm_id

tank_id

tank_integrity

tank_slurry_volume

tank stabil ization date

wasté tank temperature

total_jet_pumped_l iquid

total waste_volume

tank_use

wastēenaterial 


\subsection{SAMPLE RELATION TABLE}

\section{(HEIS Database Table Name: sample_relation)}

\section{INTRODUCTION}

SOURCE

\section{REQUIREMENTS}

Dependencies

Special Processing

Code Lookup/

Validation

Required Fields
The Sample Relation table relates two samples together. An example is a set of segment samples that make up a core composite. Each of the segment samples existed as an independent entity and now make up a new sample entity called the core composite. The Sample Relation table connects them. The Sample Relation form is shown in Figure 3.9-1.

Figure 3.9-1. Sample Relation Form.

Sample Relation

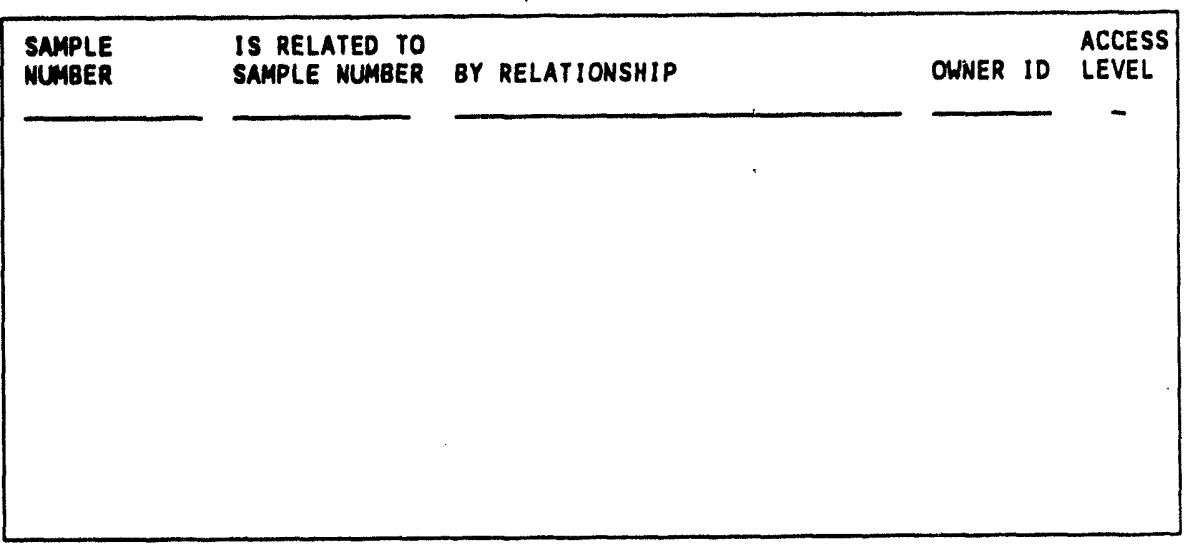

The analytical laboratory provides the data for this table.

Sample Number and Related Sample Number must exist in the Sample table.

None.

Relationship

Relationship Related Sample Number* Sample Number* 
Section

Page

Date

$$
3.9
$$

2 of 2

$04 / 15 / 94$

Recommended Query Fields

\author{
Choice 1 - Sample Number \\ Related Sample Number
}

Choice 2 - Related Sample Number
FORM FIELD NAMES/ DATABASE FIELD NAMES
Form Field Name

Relationahip

Related Semple Number

Semple Number
Database Field Name

relationship

related_samp_num 


\subsection{SAMPLE GROUP TABLES}

\subsubsection{SAMPLE GROUP TABLE \\ (HEIS Database Table Name: sample_group)}

\section{INTRODUCTION}

SOURCE

\section{REQUIREMENTS}

Dependencies

Special Processing
The Sample Group table provides the means to manage sample information by grouping samples into a set whose members are determined by the user. Groups can be named and described for viewing and reporting. This table does not alter sample data. The Sample Group form is shown in Figure 3.9.1-1.

Figure 3.9.1-1. Sample Group Form.

Sample Group

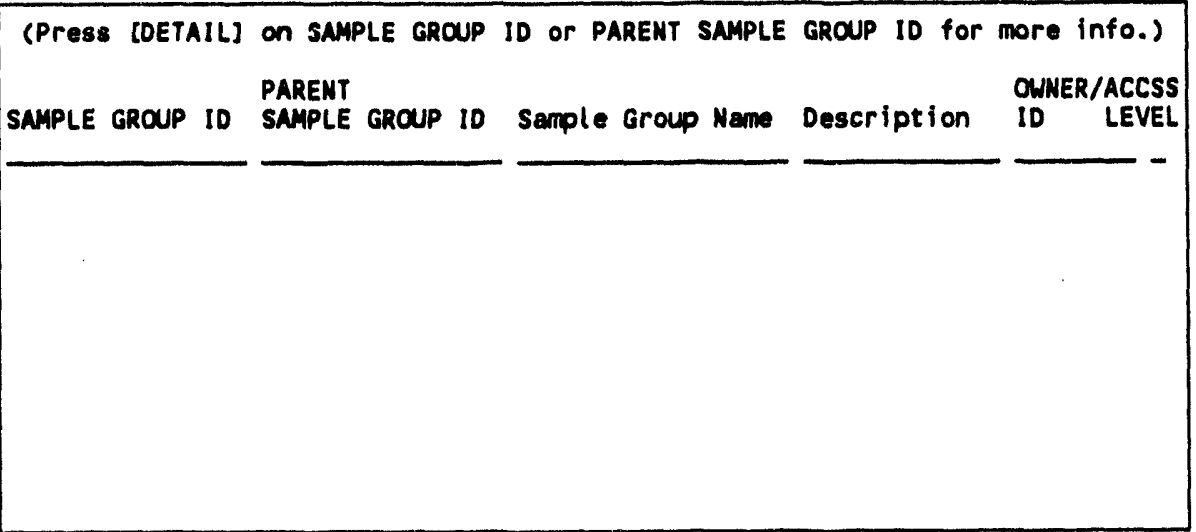

The data owner or user provides the data for this table.

Parent Sample Group ID must exist in the Sample Group table.

Parent Sample Group ID is set to ROOT (i.e., a sample group with no parent) when you enter a Sample Group ID.

Parent Sample Group ID may be modified by entering the Parent Sample Group ID field, deleting ROOT, and inserting the correct ID. 
Section

Page

Date
3.9 .1

2 of 2 $01 / 14 / 94$

Code Lookup/

Validation

Required Fields

Recommended Query Fields

None.

Parent Sample Group ID* Sample Group ID*

Choice 1 - Sample Group ID Parent Sample Group ID

Choice 2 - Parent Sample Group ID
FORM FIELD NAMES/ DATABASE FIELD NAMES

\section{Form Field Name}

Description

Parent Sample Group ID

Sample Group Name

Sample Group 10

\section{Database Field Mane}

samp_group_desc parent_sample_group_id

samp_group_name samp_group_id 


\subsubsection{SAMPLE GROUP ELEMENT TABLE}

(HEIS Database Table Name: sample_group_element)

INTRODUCTION

SOURCE

\section{REQUIREMENTS}

Dependencies

Special Processing

Code Lookup/

Validation

Required Fields
The Sample Group Element table provides the means to correlate a sample with a sample group. It includes the sample number and the sample group identifier. The Sample Group Element form is shown in Figure 3.9.2-1.

Figure 3.9.2-1. Sample Group Element Form.

Sample Group Element

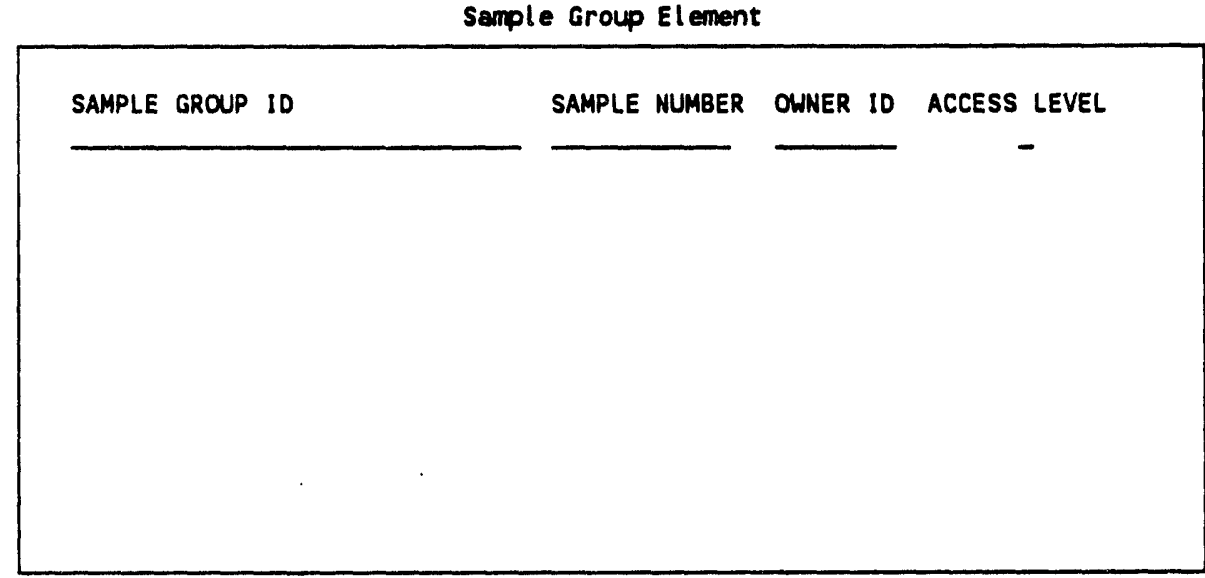

The data owner or user provides the data for this table.

Sample Group ID must exist in the Sample Group table. Sample Number must exist in the TCD Sample table. None.

None.

Sample Group ID * Sample Number* 


$\begin{array}{lrr}\begin{array}{l}\text { Section } \\ \text { Page }\end{array} & 3.9 .2 & \text { DOE/RL-93-24-8 } \\ \text { Date } & 01 / 14 / 94 & \\ & & \\ \text { Recommended Query } & \text { Choice } & 1-\begin{array}{r}\text { Sample Group ID } \\ \text { Fields }\end{array}\end{array}$

FORM FIELD NAMES/ DATABASE FIELD NAMES

\author{
Form field vene \\ Semple Group ID \\ Semple Number
}

\author{
Database Field Hame \\ semp_group_id \\ semp_num
}




\subsection{SAMPLE GROUP TABLES}

\subsubsection{SAMPLE GROUP TABLE}

(HEIS Database Table Name: sample_group)

INTRODUCTION

SOURCE

\section{REQUIREMENTS}

Dependencies

Special Processing
The Sample Group table provides the means to manage sample information by grouping samples into a set whose members are determined by the user. Groups can be named and described for viewing and reporting. This table does not alter sample data. The Sample Group form is shown in Figure 3.10.1-1.

Figure 3.10.1-1. Sample Group Form.

Sample Group

(Press [DETAIL] on SAMPLE GROUP ID Or PARENT SAMPLE GROUP ID for more info.) PARENT

SAMPLE GROUP ID SAMPLE GROUP ID Sample Group Name Description ID LEVEL $\longrightarrow$

The data owner or user provides the data for this table.

Parent Sample Group ID must exist in the Sample Group table.

Parent Sample Group ID is set to ROOT (i.e., a sample group with no parent) when you enter a Sample Group ID.

Parent Sample Group ID may be modified by entering the Parent Sample Group ID field, deleting ROOT, and inserting the correct ID. 
$\begin{array}{lr}\text { Section } & 3.10 .1 \\ \text { Page } & 2 \text { of } 2 \\ \text { Date } & 04 / 15 / 94\end{array}$

Code Lookup/

Validation

Required Fields

Recommended Query

Fields
None.

Parent Sample Group ID* Sample Group ID*

Choice 1 - Sample Group ID

Parent Sample Group ID

Choice 2 - Parent Sample Group ID
FORM FIELD NAMES/ DATABASE FIELD NAMES

\section{Form field Nane}

Description

Parent Sample Group ID

Sample Group Nane

Sample Group ID
Database Field Name

samp_group_desc

parent_sample_group_id

samp_group_name

samp_group_id 


\subsubsection{SAMPLE GROUP ELEMENT TABLE}

(HEIS Database Table Name: sample_group_element)

INTRODUCTION

SOURCE

REQUIREMENTS

Dependencies

Special Processing None.

Code Lookup/

Validation

Required Fields

None.
The Sample Group Element table provides the means to correlate a sample with a sample group. It includes the sample number and the sample group identifier. The Sample Group Element form is shown in Figure 3.10.2-1.

Figure 3.10.2-1. Sample Group Element Form.

Sample Group Element

The data owner or user provides the data for this table.

Sample Group ID must exist in the Sample Group table.

Sample Number must exist in the TCD Sample table.

Sample Group ID *

Sample Number* 
Section

Page

Date

3.10 .2

2 of 2

$04 / 15 / 94$

Recommended Query

Fields

FORM FIELD NAMES/

DATABASE FIELD NAMES

\section{DOE/RL-93-24-8}

$$
\begin{gathered}
\text { Choice } 1 \text { - Sample Group ID } \\
\text { Sample Number }
\end{gathered}
$$

Form Field Name

Sample Group ID

Sample Number
Database field Name

samp_group_id

samp_num 


\subsection{TCD RESULT GROUP TABLES}

\subsection{1 .1 TCD RESULT GROUP TABLE \\ (HEIS Database Table Name: tcd_result_group)}

INTRODUCTION

SOURCE

\section{REQUIREMENTS}

Dependencies

Special Processing

The TCD Result Group table provides the means for the user to manage sets of results. Groups can be named and described for viewing. This table does not alter result data. The TCD Result Group form is shown in Figure 3.11.1-1.

Figure 3.11.1-1. TCD Result Group Form.

TCD Result Group

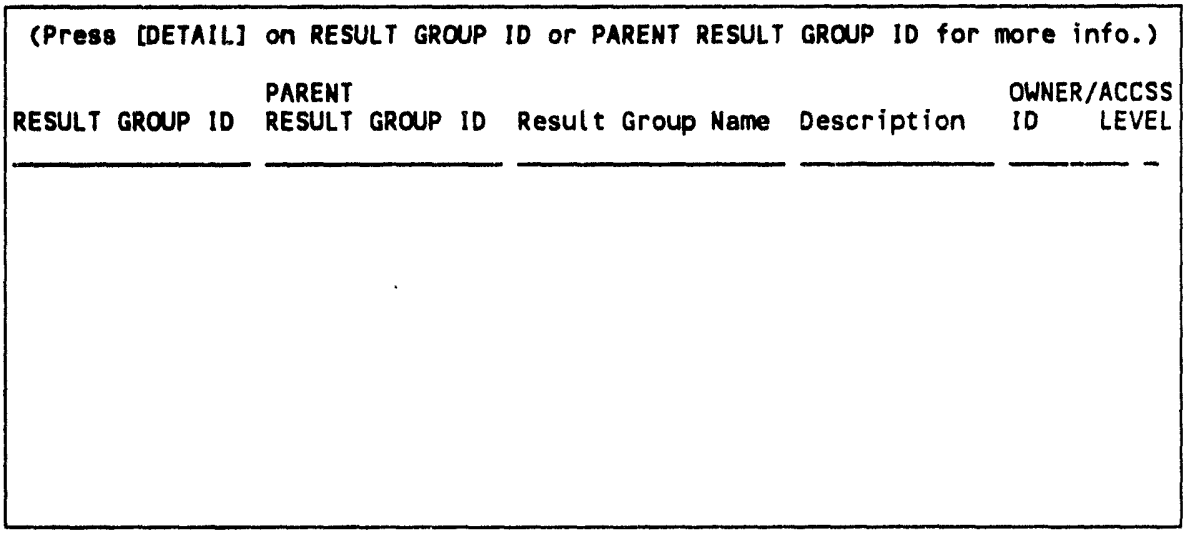

The data owner or user provides the data for this table.

Parent Result Group ID must exist in the TCD Result Group table.

Parent Result Group ID is set to ROOT (i.e., a result group with no parent) when you enter a Result Group ID.

Parent Result Group ID may be modified by entering the Parent Result Group ID field, deleting ROOT, and inserting the correct ID.

None. 


$\begin{array}{lrr}\begin{array}{l}\text { Section } \\ \text { Page }\end{array} & 3.11 .1 & \text { DOE/RL-93-24-8 } \\ \text { Date } & 2 \text { of } 2 & \\ 04 / 15 / 94 & \\ \text { Required Fields } & \begin{array}{l}\text { Parent Result Group ID* } \\ \text { Result Group ID* }\end{array}\end{array}$

Recommended Query

Fields

\author{
Choice 1 - Result Group ID \\ Parent Result Group ID \\ Choice 2 - Parent Result Group ID
}

FORM FIELD NAMES/ DATABASE FIELD NAMES

\section{Form field Neme}

Description

Parent Result Group 10

Result Group Name

Result Group 10
Database Field Name

result_group_desc

parent_result $\bar{t}_{\text {group_id }}$

result_group_ñame

result_group_id 


\subsubsection{TCD RESULT GROUP ELEMENT TABLE}

(HEIS Database Table Name: tcd_result_group_element)

\section{INTRODUCTION}

SOURCE

\section{REQUIREMENTS}

Dependencies

Special Processing

Code Lookup/

Validation

Required Fields
The TCD Result Group Element table provides the means to correlate an analysis result with a result group. It includes the result reference number and the result group identifier. The TCD Result Group Element form is shown in Figure 3.11.2-1.

Figure 3.11.2-1. TCD Result Group Element Form. TCD Result Group Element

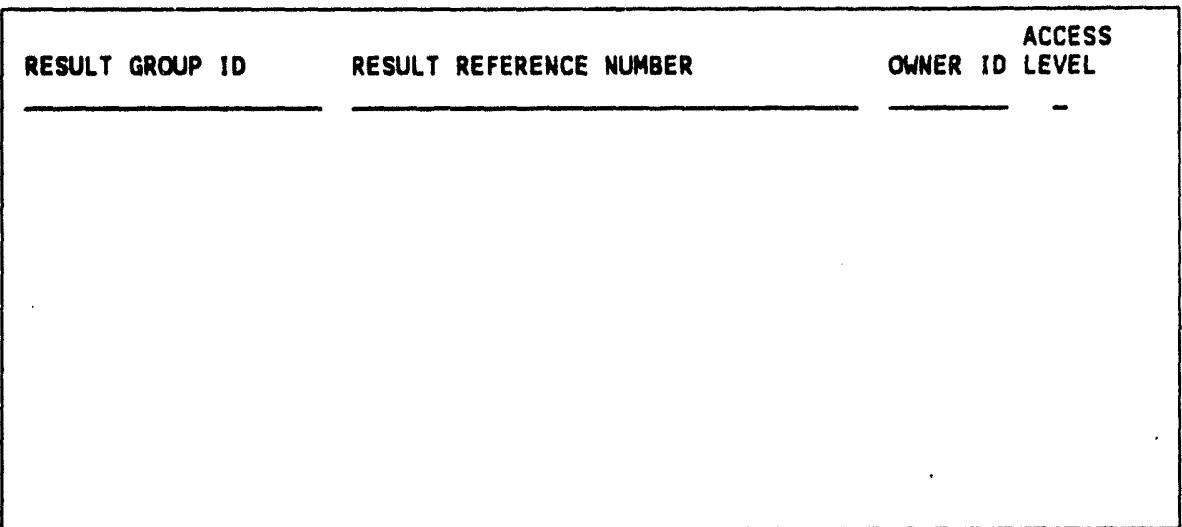

The data owner or user provides the data for this table.

Result Group ID must exist in the TCD Result Group table.

Result Reference Number must exist in the TCD Analys is Result table.

None.

None

Result Group ID*

Result Reference Number* 
Section 3.11.2

Page

Date 2 of 2 $04 / 15 / 94$

Recommended Query Fields

FORM FIELD NAMES/ DATABASE FIELD NAMES
DOE/RL-93-24-8

Choice 1 - Result Group ID

Result Reference Number

Eorm Field Mene

Result Group Io

Result Reforence Number
Database Field Name

result_group_id

rrn 


\subsubsection{TANK INVENTORY UNCERTAINTY TABLE}

(HEIS Database Table Name: tank_inventory_uncertainty)

\section{INTRODUCTION}

SOURCE

\section{REQUIREMENTS}

The Tank Inventory Uncertainty table contains statistical uncertainty values for the inventory quantity information in the Tank Inventory table. Many different uncertainty types and values can be recorded for a single entry in the Tank Inventory table. Information included on this form are the inventory uncertainty type, uncertainty value, and uncertainty units associated with a record from the Tank Inventory table.

The Tank Inventory Uncertainty form is shown in the lower portion of the form shown in Figure 3.11.3-1. The upper portion shows the Tank Inventory form, which is described in Section 3.11.2.

Figure 3.11.3-1. Tank Inventory and Uncertainty Form. Tank Inventory and Uncertainty

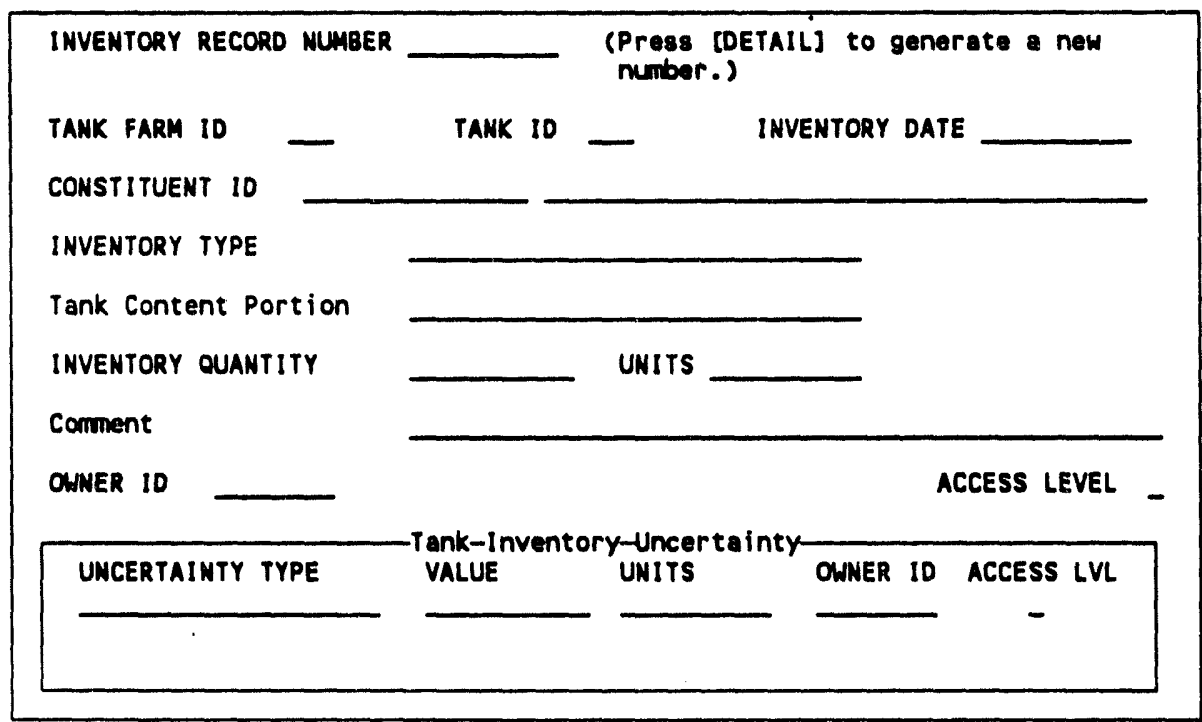

The data for this table come from analysts and statisticians who prepare the tank inventory data. 
Section 3.11.3

Page 2 of 2

Date $01 / 14 / 94$

Dependencies

Special Processing

Code Lookup/

Validation

Required Fields

Recommended Query

Fields

FORM FIELD NAMES/

DATABASE FIELD NAMES
Inventory Record Number must exist in the Tank Inventory table.

The Value field is displayed in scientific notation.

Uncertainty Type

Units

The Inventory Record Number field is required but appears only in the Tank Inventory portion of the form.

Inventory Record Number

Uncertainty Type*

Units

Value

Choice 1 - Inventory Record Number
Form field Name

Uncertainty Type

Value

Units
Database Field Name

inventory_uncertainty_type

inventory_uncertainty_value inventory_uncertainty_units 


\subsection{SAFETY CRITERIA TABLE}

\section{(HEIS Database Table Name: safety_criteria)}

\section{INTRODUCTION}

SOURCE

\section{REQUIREMENTS}

Dependencies

Special Processing

\section{Code Lookup/}

Validation

Required Fields
The Safety Criteria table contains safety parameter values used to judge the relative safety of waste tank conditions. Included in this table are the Constituent ID, the effective dates of the safety parameter value, identifying information about the source document from which the value for the safety parameter was determined, and the safety criteria value and units. The Safety Criteria form is shown in Figure 3.12-1.

Figure 3.12-1. Safety Criteria Form.

Safety Criteria

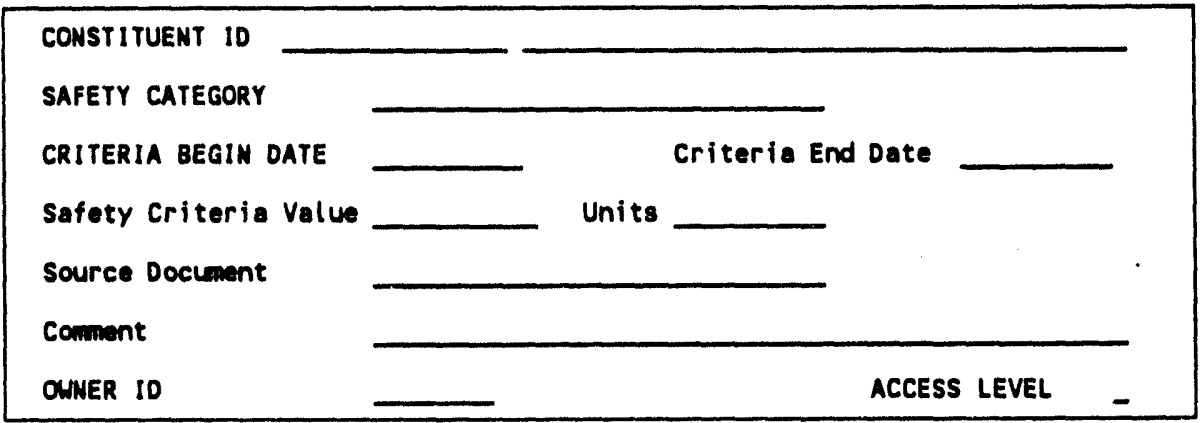

The data for this table come from the source documents described in the records.

Constituent ID must exist in the Constituent table.

The Safety Criteria Value field is displayed in scientific notation.

Constituent ID

Safety Category

Units

Constituent ID*

Criteria Begin Date*

Safety Category* 
Section

Page

3.12

Date

2 of 2

$01 / 14 / 94$

Recommended Query

Fields

FORM FIELD NAMES/

DATABASE FIELD NAMES

\author{
Choice 1 - Constituent ID \\ Safety Category \\ Criteria Begin Date
}

\section{Eorm Field Mame}

Cominent

Constituent ID

Criteria Begin Date

Criteria End Date

Safety Category

Source Document

Safety Criteria Value

Units
Detebase Field Hems

safety_criteris_comment con_id

criterie_begin_date

criterisend date

safety_cātegöry

src_doce

safety_criteria_units 


\subsection{TANK INVENTORY TABLES}

\subsubsection{TANK INVENTORY SOURCE TABLE}

(HEIS Database Table Name: tank_inventory_source)

\section{INTRODUCTION}

The Tank Inventory Source table contains reference information about the origins of the data contained in the Tank Inventory table. Information included are the type of inventory source, the source report document number, the basis for the inventory, the date the inventory was released, the Tank ID, and the Tank Farm ID. The Tank Inventory Source table form is shown in Figure 3.12.1-1.

Figure 3.12.1-1. Tank Inventory Source Form.

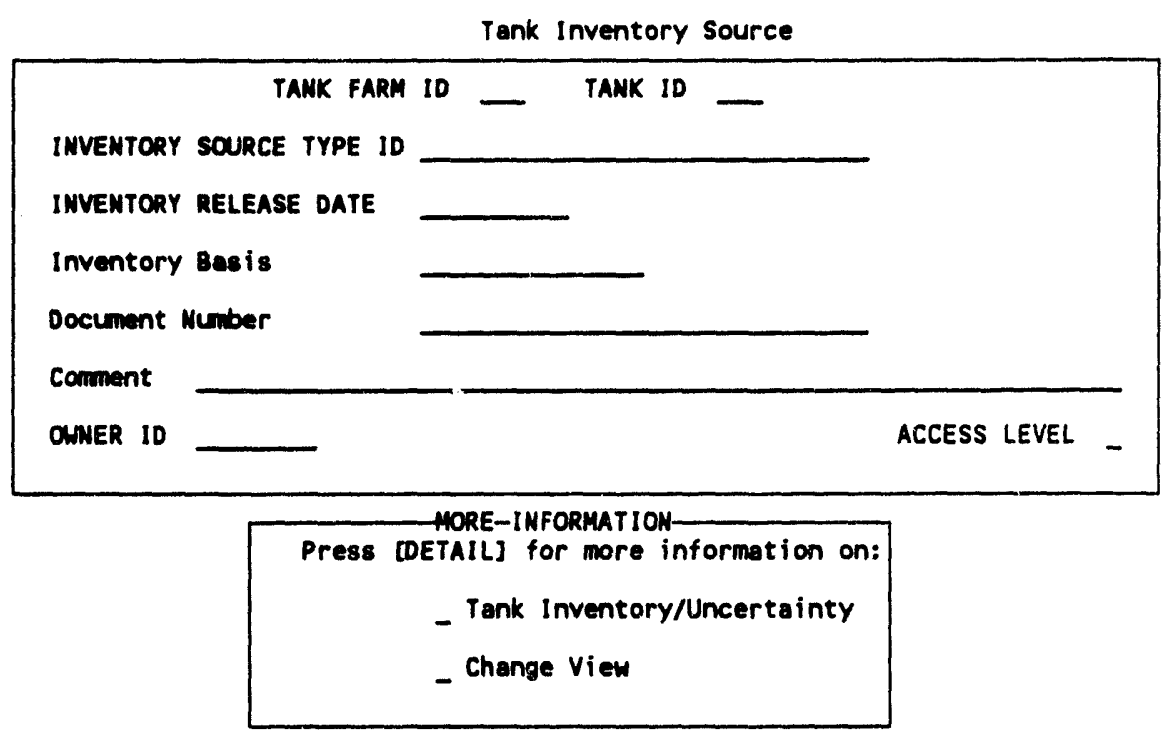

The data for this table come from characterization reports or other reports that quantify the contents of waste tanks. 
Section

Page

Date

3.12 .1

2 of 2

$04 / 15 / 94$

\section{REQUIREMENTS}

Dependencies

Special Processing

Code Lookup/

Validation

Required Fields

Recommended Query Fields
The combination of Tank Farm ID and Tank ID must exist in the Waste Tank table.

The Document Number, if any, must exist in the TCD Document Reference table.

The Inventory Source Type ID must exist in the Inventory Source Type table.

None.

Document Number

Inventory Basis

Inventory Source Type ID

Tank Farm ID

Inventory Release Date*

Inventory Source Type ID*

Tank Farm ID*

Tank ID*

Choice 1 - Tank Farm ID

Tank ID

Inventory Source Type ID

Inventory Release Date
FORM FIELD NAMES/ DATABASE FIELD NAMES

\section{Form field Mene}

Comment

Document Mumber

Inventory Basis

Inventory Release Date

Inventory source Type ID

Tank Farm 10

Tank ID
Database field Name

inventory_src_comment doc_num

inventory basis

inventory release date

inventory_src_type_id

tank_farm_id 


\subsubsection{INVENTORY SOURCE TYPE TABLE}

(HEIS Database Table Name: inventory_source_type)

INTRODUCTION

SOURCE

\section{REQUIREMENTS}

Dependencies

None.

Special Processing None.

Code Lookup/

Validation

None.
Tank inventories have been estimated via several different methods, referred to as source types. The Inventory Source Type table contains general descriptions of these estimation methods. Information included are the inventory source type identifier, a name and address for a contact who is knowledgeable about the inventory source type, and a general description of the inventory source type. The Inventory Source Type table form is shown in

Figure 3.12.2-1.

Figure 3.12.2-1. Inventory Source Type Form Inventory Source Type

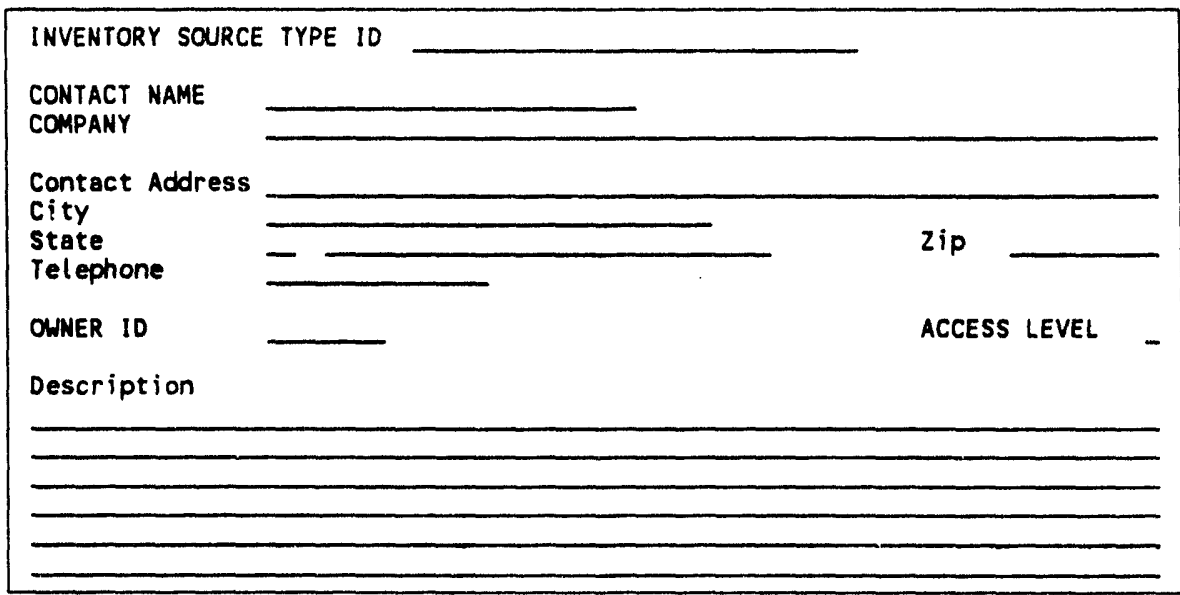

The data for this table come from characterization experts knowledgeable about the sources of tank inventories. 


$\begin{array}{lr}\text { Section } & 3.12 .2 \\ \text { Page } & 2 \text { of } 2 \\ \text { Date } & 04 / 15 / 94\end{array}$

Required Fields

Contact Company

Contact Name

Inventory Source Type ID*

Recommended Query

Fields

Choice 1 - Inventory Source Type ID

FORM FIELD NAMES/ DATABASE FIELD NAMES

Form field Neme

City

Contact Address

Contect Compary

Contact Name

Description

Inventory Source Type 10

State

Telephone

Zip
Database Field Name

contact_city

contact_address

contact company

contact_name

inventory_src_type_desc

inventory sre_type_id

contact state

contact phone num

contact_zip_códe 


\subsubsection{TANK INVENTORY TABLE}

\section{(HEIS Database Table Name: tank_inventory)}

\section{INTRODUCTION}

SOURCE

\section{REQUIREMENTS}

Dependencies
The Tank Inventory table contains estimated tank inventories of individual constituents. The constituent inventory data may be represented in concentrations or in bulk amounts. Inventories may represent either the bulk contents of the tank or a specific portion of the tank, such as a particular layer or phase. This table also stores values for constituents used to evaluate a tank's contents relative to established safety criteria.

Inventory data may come from a variety of types of sources, and different source types use different units of measure. To compare constituent inventories from different sources, common units are needed. To support the need for common units, the Tank Inventory table includes the unit category to describe the type of units being used, an input inventory quantity and units, and a converted input quantity and units.

Other information included in this table are the constituent ID, inventory type, date of inventory release, tank ID, tank farm ID, inventory record number, load date, last modification date, change indicator, and a comment. The Tank Inventory form is shown in the upper half of the form shown in Figure 3.12.3-1. The lower half shows the uncertainty measures associated with the inventory record. The Tank Inventory Uncertainty table is described in Section 3.12.4.

The data for this table come from characterization reports or other reports that quantify the contents of waste tanks.

The combination of Tank Farm ID, Tank ID, Inventory Source Type ID, and Inventory Release Date must exist in the Tank Inventory Source table.

Constituent ID must exist in the Constituent table. 
Section

Page

Date

3.12 .3

2 of 4

$04 / 15 / 94$

Figure 3.12.3-1. Tank Inventory and Uncertainty Form. Tank Inventory and Uncertainty

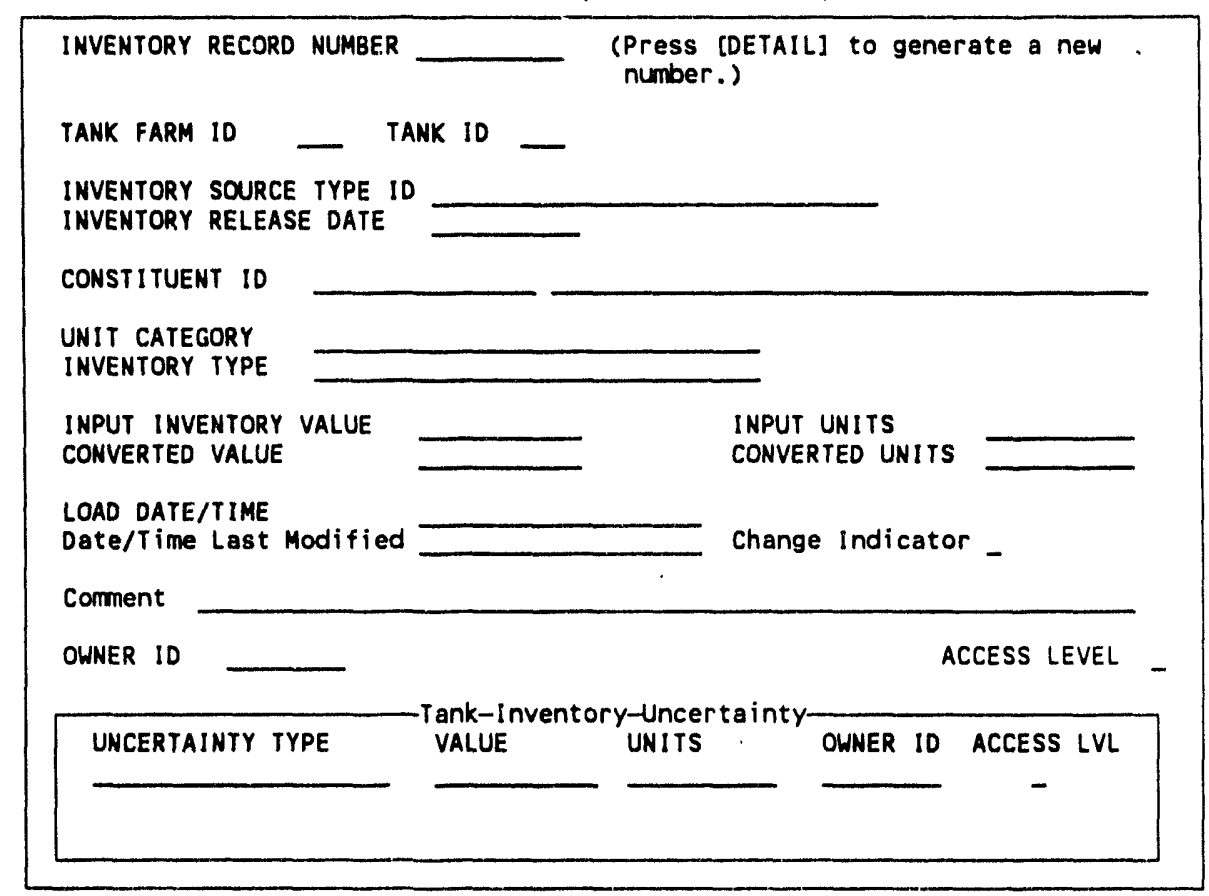

Inventory Record Number must be system generated.

The following fields are displayed in scientific notation. Instructions for fields displayed in scientific notation are found in Section 4.3.4 of the HEIS User's Guide (DOE/RL 1994a).

Converted Value

Input Inventory Value

The Converted Value and Converted Units are system generated based on the Input Inventory Value, Input Units, and Unit Category.

Change Indicator is system generated.

Load Date/Time is system generated.

Date/Time Last Modified is system generated. 
Code Lookup/ Validation

Required Fields

Recommended Query Fields

\author{
Constituent ID \\ Converted Units \\ Inventory Source Type ID \\ Inventory Type \\ Input Units \\ Tank Farm ID \\ Unit Category
}

Constituent ID

Converted Value

Converted Units

Input Inventory Value

Input Units

Inventory Release Date

Inventory Record Number*

Inventory Source Type ID

Inventory Type

Load Date/Time

Tank Farm ID

Tank ID

Unit Category

Choice 1 - Inventory Record Number
Choice 2 - Tank Farm ID
Tank ID
Inventory Source Type ID
Inventory Release Date
Constituent ID
Unit Category
Inventory Type

\section{FORM FIELD NAMES/ DATABASE FIELD NAMES}

\author{
Form Field Name \\ Change Indicator \\ Comment \\ Converted Units \\ Converted Value \\ Constituent 10 \\ Date/Time Last Modified \\ Input Inventory Value \\ Input Units \\ Inventory Release Date \\ Inventory Source Type ID \\ Inventory Record Number \\ Inventory Type \\ Load Date/Time \\ Tank Farm ID \\ Tank 10 \\ Unit Category
}

\author{
Database Field Name \\ change indicator \\ inventory_src_comment \\ conv inveñtory_units \\ conv inventory_value \\ con_id \\ date_last_modified \\ input inventory value \\ input_inventory_units \\ inventory_release_date \\ inventory_src_type_id \\ inventory_rec_num \\ inventory_type \\ load date time \\ tank farm id \\ tank_id \\ unit_category
}




$$
\begin{aligned}
& \text { 品䅉誉 } \\
& \text { 으 }
\end{aligned}
$$

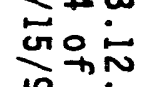

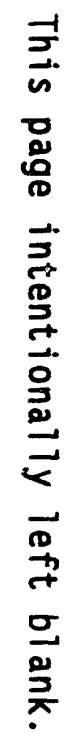

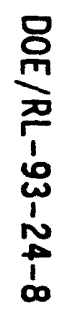




\subsubsection{TANK INVENTORY UNCERTAINTY TABLE}

(HEIS Database Table Name: tank_inventory_uncertainty)

INTRODUCTION
The Tank Inventory Uncertainty table contains statistical uncertainty values for the inventory quantity information in the Tank Inventory table. Many different uncertainty types and values can be recorded for a single entry in the Tank Inventory table. Information included on this form are the inventory uncertainty type, uncertainty value, and uncertainty units associated with a record from the Tank Inventory table.

The Tank Inventory Uncertainty form is shown in the lower portion of the form shown in Figure 3.12.4-1. The upper portion shows the Tank Inventory form, which is described in Section 3.12.3.

Figure 3.12.4-1. Tank Inventory and Uncertainty Form. Tank Inventory and Uncertainty

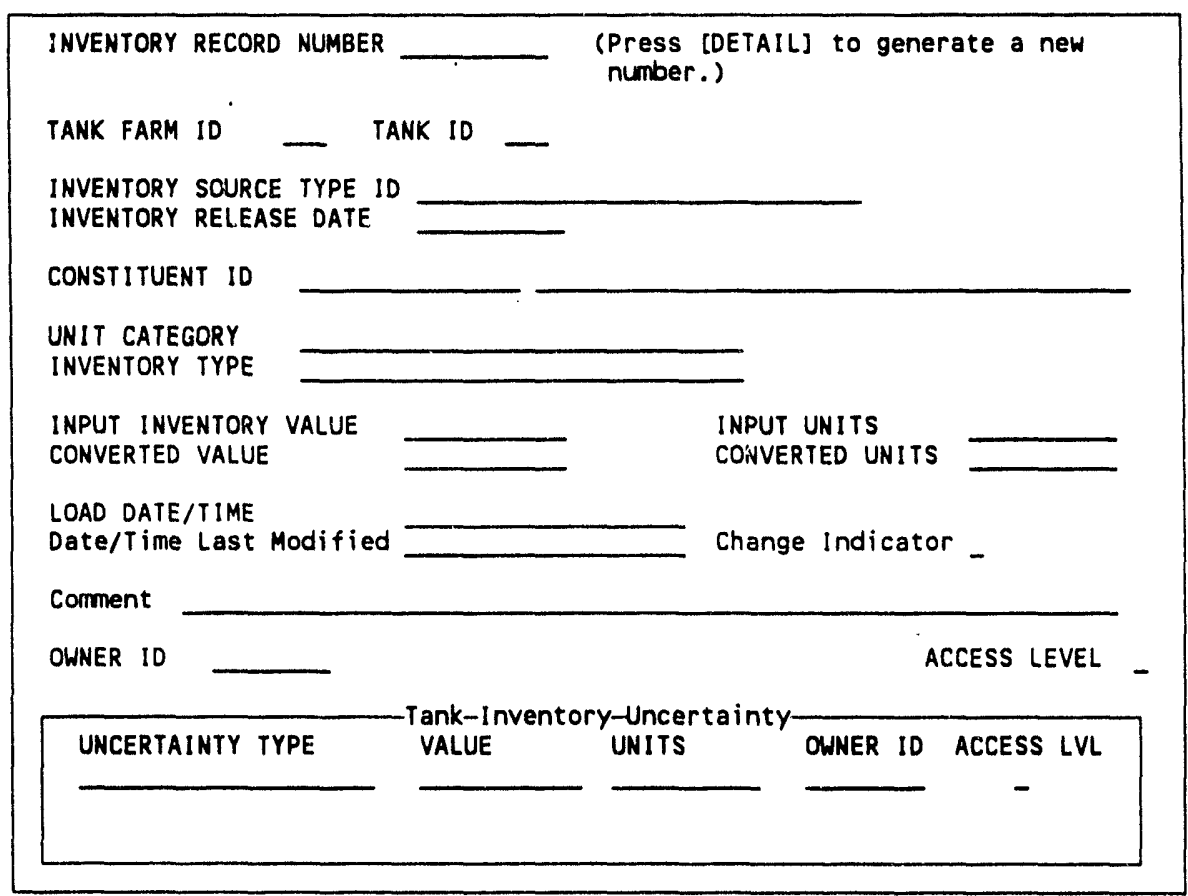

SOURCE
The data for this table come from characterization reports or other reports that quantify the contents of waste tanks. 
Section

Page

Date 3.12 .4

2 of 2

$04 / 15 / 94$

\section{REQUIREMENTS}

Dependencies

Spectal Processing

Code Lookup/

Validation

Required Fields

Recommended Query Fields

FORM FIELD NAMES/

DATABASE FIELD NAMES
Inventory Record Number must exist in the Tank Inventory table.

The Value field is displayed in scientific notation. Instructions for fields displayed in scientific notation are found in Section 4.3.4 of the HEIS User's Guide (DOE/RL 1994a).

Uncertainty Type

Units

The Inventory Record Number field is required but appears only in the Tank Inventory portion of the form.

Inventory Record Number Uncertainty Type*

Units

Value

Choice 1 - Uncertainty Type Units

Form Field Name Uncertainty Type Value

Database field Name

inventory_uncertainty_type

inventory_uncertainty_value inventory_uncertainty_units 


\subsubsection{TANK INVENTORY CHANGE TABLE}

(HEIS Database Table Name: tank_inventory_change)

INTRODUCTION

The Tank Inventory Change table contains a timestamped historical record of changes made to tank inventory records. Some aspects of the inventory, such as input value and units, are subject to change. The reason for the change, the change authority and user name, the change code, and the date/time of change also are stored. The Tank Inventory Change View form shown in Figure 3.12.5-1 provides a way to view this historical record. To access this form, choose the "Tank Inventory Change View" option on the TCD Tank Data menu.

Figure 3.12.5-1. Tank Inventory Change View Form.

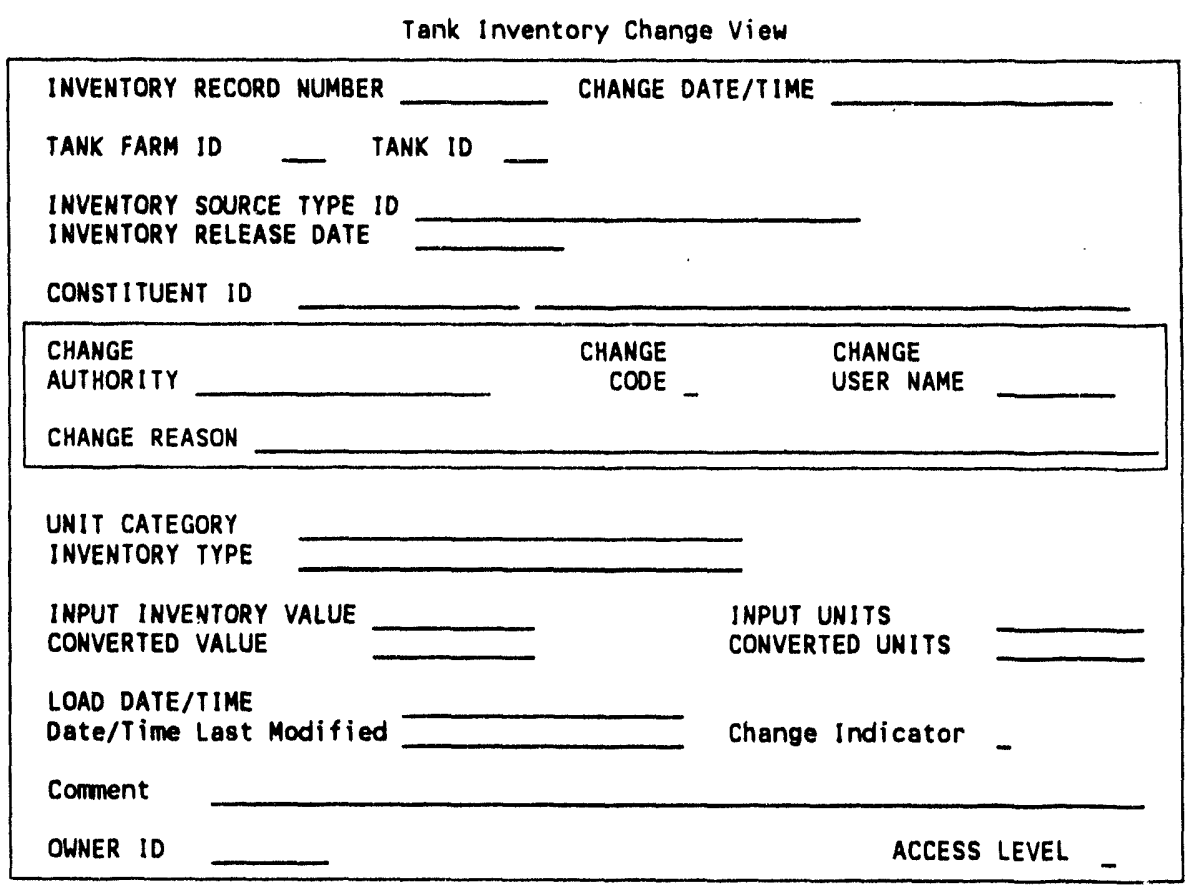

SOURCE

The source of the data is a previous record in the Tank Inventory table. These records are generated automatically when an inventory record is modified or deleted. See Section 4.3.5 of the HEIS User's Guide (DOE-RL 1994a) for details. 
Section

3.12 .5

Page

2 of 2

Date

$04 / 15 / 94$
Code Lookup/

Validation

Required Fields

Recommended Query Fields

"Dependencies" and "Special Processing" are the same as found in the Tank Inventory table (see

Section 3.12.3). The "Required Fields," "Code Lookup/Validation," and "Form Field Name/Database

Field Name" lists are the same with the exception of specific changes listed in the sections below. A complete description of the change record generation process is found in Section 4.3 .5 of the HEIS User's Guide.

All fields in the Tank Inventory table plus -

Change Code

Change Reason

All fields in the Tank Inventory table plus -

Change Authority

Change Code

Change Date/Time

Change Reason

Change User Name

Choice 1 - Inventory Record Number Change Date/Time

Choice 2 - Tank Farm ID

Tank ID

Inventory Source Type ID

Inventory Release Date

Constituent ID

Unit Category

Inventory Type

FORM FIELD NAMES/

DATABASE FIELD NAMES

All fields in the Tank Inventory table plus -

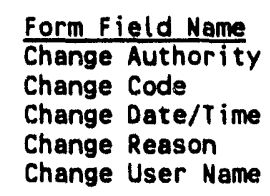

Database Field Name

change_authority

change_code

change_date_time

change reasōn

change_user_name 


\subsubsection{TCD DOCUMENT REFERENCE TABLE}

(HEIS Database Table Name: tcd_doc_reference)

INTRODUCTION

SOURCE

\section{REQUIREMENTS}

Dependencies

Special Processing

Code Lookup/

Validation

Required Fields

Recommended Query

Fields

FORM FIELD NAMES/

DATABASE FIELD NAMES

The TCD Document Reference table contains information about formal documents that contain tank inventories. Information included are the identifying document number, the document name, author, and rublication date. The TCD Document Reference table form is shown in Figure 3.12.6-1.

Figure 3.12.6-1. TCD Document Reference Form.

TCD Document Reference

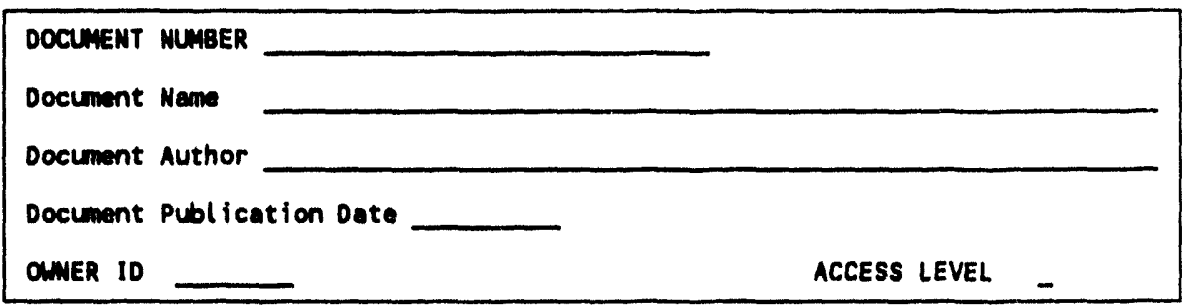

The data for this table come from characterization reports or other reports that quantify the contents of waste tanks.

None.

None.

None.

Document Number*

Choice 1 - Document Number

Form Field Hene

Docunent Author

Document Neme

Document Number

Document Publication Date
Database Field Name

doc_author

doc_name

doc mum

doc_pub_date 
Section 3.12 .6

Page 2 of 2

Date $04 / 15 / 94$

DOE/RL-93-24-8

This page intentionally left blank. 


\subsection{SAFETY CRITERIA TABLE}

(HEIS Database Table Name: safety_criteria)

INTRODUCTION

SOURCE

\section{REQUIREMENTS}

Dependencies

Special Processing

\section{Code Lookup/} Validation

Required Fields
The Safety criteria table contains safety parameter values used to judge the relative safety of waste tank conditions. Included in this table are the Constituent ID, the effective dates of the safety parameter value, identifying information about the source document from which the value for the safety parameter was determined, and the safety criteria value and units. The Safety criteria form is shown in Figure 3.13-1.

Figure 3.13-1. Safety Criteria Form.

Safety Criteria

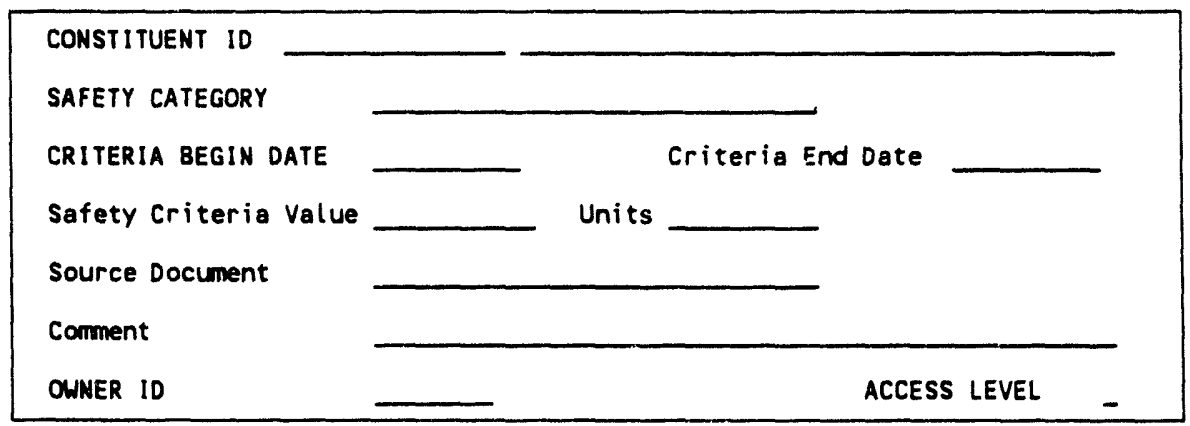

The data for this table come from the source documents described in the records.

Constituent ID must exist in the Constituent table.

The Safety Criteria Value field is displayed in scientific notation. Instructions for fields displayed in scientific notation are found in Section 4.3.4 of the HEIS User's Guide (DOE/RL 1994a).

Constituent ID

Safety Category

Units

Constituent ID*

Criteria Begin Date*

Safety Category* 
Section

Page

Date

3.13

2 of 2

$04 / 15 / 94$

Recommended Query Fields

\section{FORM FIELD NAMES/}

DATABASE FIELD NAMES

\author{
Choice 1 - Constituent ID \\ Safety Category \\ Criteria Begin Date
}

Form field Name

Comment

Constituent ID

Criteria Begin Date

Criteria End Date

Safety Cotegory

Source Document

Safety Criteria Value

Units
Database Field Name

sofety_criteria_comment

con_id

crifteria_begin_date

criteria-end date

safety_category

src_doc

saféty_criteria_value safety_criteria_units 


\subsection{THE TANK CHARACTERIZATION DATA (TCD) REPORTS}

INTRODUCTION

INTRODUCTION
The Tank Characterization Data (TCD) subject area reports use Structured Query Report Writer (SQR) (SQ Software 1990). Refer to the HEIS User's Guide (DOE/RL 1994a), Chapter 6.0, for an overview of how to run these predefined SQR reports.

When you run a report, the text for that report is written to a file. Chapter 6.0 describes how to print the file containing your report on your local printer.

\subsection{STATISTICIAN'S REPORT}

The Statistician's Report lists all analytical result information for a tank core. It is designed to support the needs of statisticians producing tank inventory calculations for Tank Characterization Reports (TCRs). The output of the Statistician's Report is a bar-delimited file containing. TCD Analys is and TCD Analysis Result data for a core.

The following lists the prompts you can expect to see after you begin running the reporting software.

Explanations are given below.

Filename for output (tcd_stat_report.1 is = default):

Enter the Tank Farm (or Exit):

Enter the Tank ID (or Exit):

Enter the Tank Core (or Exit):

Enter the minimum ACCESS LEVEL $(9=$ defaut $t)$ :

1. To start the Statistician's Report program, enter the following at the \% prompt:

$$
\text { stat_rpt }
$$

2. The \% prompt will disappear. You will then be prompted for an output file name. Enter the name for the report output file, or press [ENTER] to choose the default when you see this message:

Filename for output (icd_stat_report.lis = default):

3. You will be prompted for the Tank Farm containing the tank you are interested in. You can type your response in upper, lower, or mixed case. If 
you want to quit without generating a report, type Exit at the prompt:

\section{Enter the Tank Farm (or Exit): $\mathbf{X X X}$}

4. You will be prompted for the Tank ID from which the core was taken. If you want to quit without generating a report, type Exit at the prompt:

\section{Enter the Tank ID (or Exit): 999}

5. You will be prompted for the Core ID for which you want to report. If you want to quit without generating a report, type Exit at the prompt:

Enter the Core ID (or Exit): 99

6. The Access Level is a number between $0-9$, with 0 accessing all information available to you, 9 accessing only information that has been verified and validated, and numbers in between 0 and 9 accessing information at various points in the verification and validation process. Supply the desired Access Level at the prompt:

Enter the minimum ACCESS LEVEL $(9=$ default):0

7. The reporting program has completed its run when you see the following message:

SQR: End of Run.

8. The report is stored in the output file name you input in step 2 .

Error Checking

Output Format
This program checks your inputs to make sure that the tank core you request exists. If not, you are asked to re-enter your inputs.

The Statistician's Report produces a wide (greater than 132-character column) output file that serves as input to programs written by statisticians. It contains several types of records. The first line of the file contains the file header. Table 4.1-1 illustrates the file header format. It contains the information specified in the report request.

The remainder of the file is made up of header and detail records for documenting the analyses and results done on the core. The analyses are documented in the header records and the individual results are 
Table 4.1-1. File Header Record Layout.

\begin{tabular}{lllll}
\hline Column field Name & Type(size) & Required & \multicolumn{1}{c}{ Contents } \\
\hline A & Record Type & CHAR(1) & Yes & $\begin{array}{l}\text { Contains the letter A, which signifies a file header } \\
\text { record. }\end{array}$ \\
B & File Name & CHAR & Yes & As specified in report request. \\
C & Tank Farm 10 & CHAR(6) & Yes & As specified in report request. Example: sY101 \\
D & Core ID & NUMBER(5) & Yes & As specified in report request. \\
$E$ & Access Level & NUMBER(1) & Yes & As specified in report request. \\
\hline
\end{tabular}

documented in the detail records. The format of the header records is shown in Table 4.1-2, while the format of the detail records is shown in Table 4.1-3. A header record is followed by zero-to-many result detail records. Following the last detail record in the set, a row appears containing the record type "D" in the first field and a line of asterisks in the second field.

Within the file, the header records are sorted in order first by Segment ID, with all core composites appearing at the end of the file. The header records are sorted next by the Master Sample, the HEIS Sample Number, and then by the Analys is Method ID.

A set of result records for a header is sorted first by CAS Code and then by Analytical Result Type.

All analytical result values included in TCD for a sample are included in the set of detail records. This includes blanks and spikes.

The laboratory appears to report a single detection limit for the primary, duplicate, blank, and spike results for a particular constituent and a particular analysis. Consequently, the report displays the same detection limit and associated units on each detail record if a detection limit value is known for the constituent and analysis. The unit of measure for the detection limit may not be the same as the unit of measure on the corresponding analytical result. If multiple detection limits are found for a single sample analysis on a single constituent in a single laboratory, one of the detection limits is reported but no information about the multiple occurrence of detection limits is provided. 
Table 4.1-2. Header Record Layout.

\begin{tabular}{|c|c|c|c|c|}
\hline Column & Field Name & Type(size) & Required & Contents \\
\hline A & Record Type & CHAR(1) & Yes & $\begin{array}{l}\text { Contains the letter } B \text {, which signifies an analysis header } \\
\text { record. }\end{array}$ \\
\hline B & Segment ID & CHAR (22) & Yes & $\begin{array}{l}\text { If the analysis was done on a segment sample, this } \\
\text { contains the segment number. For a core composite, it } \\
\text { contains the words "Core Composite." For a tank } \\
\text { composite, it contains the words "Tank Composite," and for } \\
\text { a multi-source (multiple tanks or tank samples combined } \\
\text { with non-tank samples), it contains the words "Multi } \\
\text { source Composite." }\end{array}$ \\
\hline
\end{tabular}

Lab Sample 10

CHAR(12)

P

R

s

$T$

Dilution Factor NUMBER(15,7) Yes

CHAR(20)

CHAR(20)

CHAR(20)

CHAR(20)

CHAR(20)

C. $\operatorname{AR}(20)$

CHAR (150)

CHAR(240)

CHAR(240)
No

Yes

Yes

Yes

Yes

Yes

Yes

Yes

Yes

Yes

No

No

No

No

No

No

No

HEIS Sample Number associated with the segment or the core composite.

KEIS Sample Number associated with the sample being analyzed.

TCD-generated method identifier corresponding to the analytical procedure and primary sample preparation.

Name of the chemical analysis. This is a name, not a series of abbreviations.

Abbreviation for the name of the lab performing the analysis.

Phase of the sample taken from the core: $S=$ solids; $L=$ drainable liquids.

rext indicating whether the sample was taken from the top, middle, or bottom of the segment. Examples: TOP, BOTTON, TOTAL

Lab sample identifier assigned by laboratory to the sample corresponding to the primary analysis result. May be empty if the analysis was performed on a combination of several lab sample IDs or if the analys is (such as a physical analysis) was done on the entire segment.

Example: 100 for 1:100 or .01 for 10:1

Lab Procedure used for the analysis. Example: PNL-211

Primary laboratory procedure used for sample preparation. Example: PNL-101, NONE

Sccondary laboratory procedure used for sample preparation. Example: PNL-101

Example: 09-JUN-92 09:25:11

Example: J D Smith

Example: 813

EXample: CORE 36 DATA REPORT Tank 241-SST-C-112 September 30, 1992

Lab-generated identifier for data file from which the enalytical result data were loaded.

Comment about the analysis. Provides additional context. May contain list of lab sample IDis if the analysis was run on combiration of several lab samples. 
Table 4.1-3. Detail Record Layout.

\begin{tabular}{|c|c|c|c|c|}
\hline Column & Field Name & Type(size) & Required & Contents \\
\hline A & Record Type & CHAR(1) & Yes & $\begin{array}{l}\text { Contains the letter } C \text {, which signifies a result detail } \\
\text { record. }\end{array}$ \\
\hline 8 & Result Ref. \# & NUMBER(20) & Yes & Unique number assigned to this result in TCD. \\
\hline C & Constituent ID & CHAR(60) & Yes & $\begin{array}{l}\text { Name or abbreviation for the constituent or property } \\
\text { Examples: Aluminum; Mass }\end{array}$ \\
\hline D & CAS Code & CHAR (15) & Yes & $\begin{array}{l}\text { Chemical Abstract Services name for the constituent, or a } \\
\text { standard internal name for a property. Examples: } \\
14265-44-2 \text {; MASS }\end{array}$ \\
\hline $\mathbf{E}$ & Analys is Result & NUMBER & No & Resulting measurement for one constituent Example: 581.6 \\
\hline $\mathbf{F}$ & $\begin{array}{l}\text { Analys is Result } \\
\text { Type }\end{array}$ & CHAR(20) & Yes & $\begin{array}{l}\text { What the analysis result represents. Example: } \\
\text { DUPLICATE_RESULT }\end{array}$ \\
\hline G & $\begin{array}{l}\text { Analysis Result } \\
\text { Units }\end{array}$ & CHAR(10) & Yes & $\begin{array}{l}\text { Engineering Units associated with the analysis result. } \\
\text { Example: } u g / L\end{array}$ \\
\hline H & Result Uncertainty & NUMBER & No & Uncertainty associated with the analysis result. \\
\hline I & $\begin{array}{l}\text { Result Uncertainty } \\
\text { Units }\end{array}$ & CHAR(10) & No & Units associated with result uncertainty. Example: \% \\
\hline J & Result Qualifiers & CHAR(6) & No & $\begin{array}{l}\text { Up to } 6 \text { characters representing data qualifiers, report } \\
\text { flags, and validation flags. Example: } U \text { (indicating } \\
\text { material was analyzed for but not detected). }\end{array}$ \\
\hline K & Detection Limit & NUMBER & No & $\begin{array}{l}\text { Instrument detection limit associated with a particular } \\
\text { analysis for a specific constituent. Example: } 133.83\end{array}$ \\
\hline L & $\begin{array}{l}\text { Detection Limit } \\
\text { Units }\end{array}$ & CHAR(10) & No & $\begin{array}{l}\text { Engineering units associated with the detection limit } \\
\text { value. Example: mg } \mathbf{k g}\end{array}$ \\
\hline M & Analysis Date/Time & CHAR(20) & No & $\begin{array}{l}\text { Date and time the analysis was performed. Example: } \\
10-U L-2 \quad 11: 42: 14\end{array}$ \\
\hline N & Blank & & & \\
\hline 0 & Blank & & & \\
\hline P & Blank & & & \\
\hline$a$ & Blank & & & \\
\hline $\mathbf{R}$ & Blank & & & \\
\hline $\mathbf{s}$ & Blank & & & \\
\hline T & Result Comment & CHAR(240) & No & Corment about the analysis result. \\
\hline
\end{tabular}


인

产造

for
जuo
von:
son

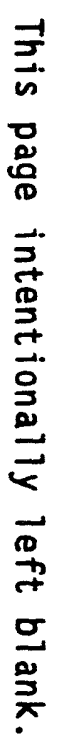

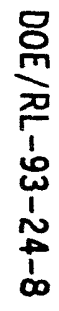




\section{REFERENCES}

\section{HEIS MANUALS}

DOE-RL, 1994a, Hanford Environmental Information System (HEIS): Volume 1 User's Guide, DOE/RL-93-24-1, U.S. Department of Energy, Richland Operations Office, Richland, WA.

DOE-RL, 1994b, Hanford Environmental Information System (HEIS): Volume 2 Operator's Guide, DOE/RL-93-24-2, U.S. Department of Energy, Richland Operations Office, Richland, WA.

DOE-RL, 1994C, Hanford Environmental Information System (HEIS): Volume 3 Subject Area Reference Manual, DOE/RL-93-24-3, U.S. Department of Energy, Richland Operations Office, Richland, WA.

DOE-RL, 1994d, Hanford Environmental Information System (HEIS): Volume 4 Wellbased Subject Areas, DOE/RL-93-24-4, U.S. Department of Energy, Richland Operations Office, Richland, WA.

DOE-RL, 1994e, Hanford Environmental Information System (HEIS): Volume 5 Surface-based Subject Areas, DOE/RL-93-24-5, U.S. Department of Energy, Richland Operations Office, Richland, WA.

DOE-RL, 1994f, Hanford Environmental Information System (HEIS): Volume 6 Soil Subject Area, DOE/RL-93-24-6, U.S. Department of Energy, Richland Operations Office, Richland, WA.

DOE-RL, 1994g, Hanford Environmental Information System (HEIS): Volume 7 Sample and Data Tracking Subject Area, DOE/RL-93-24-7, U.S. Department of Energy, Richland Operations Office, Richland, WA (to be issued).

DOE-RL, 1994h, Hanford Environmental Information System (HEIS): Volume 8 Tank Characterization Data Subject Area, DOE/RL-93-24-8, U.S. Department of Energy, Richland Operations Office, Richland, WA.

DOE-RL, 1994i, Hanford Environmental Information System (HEIS): Volume 9 Quality Control Subject Area, DOE/RL-93-24-9, U.S. Department of Energy, Richland Operations Office, Richland, WA (to be issued).

DOE-RL, 1994j, Hanford Environmental Information System (HEIS): Volume 10 Miscell aneous Material Subject Area, DOE/RL-93-24-10, U.S. Department of Energy, Richland Operations Office, Richland, WA (to be issued).

DOE-RL, 1994k, Hanford Environmental Information System (HEIS): Volume 11 Tutorial, DOE/RL-93-24-11, U.S. Department of Energy, Richland Operations Office, Richland, WA (to be issued). 
Section REFERENCES

Page 2 of 2

DOE/RL-93-24-8

Date

$01 / 14 / 94$

\section{TEXT AND TABLE REFERENCES}

WHC, 1988, Tank Farm Surveillance and Waste Status Report, WHC-EP-0182-01 et seq., Westinghouse Hanford Company, Richland, WA. 
DOE/RL-93-24-8

Section APPENDIX A

Page

Date

1 of 4

$04 / 15 / 94$

APPENDIX A

TCD DATA QUALIFIERS 


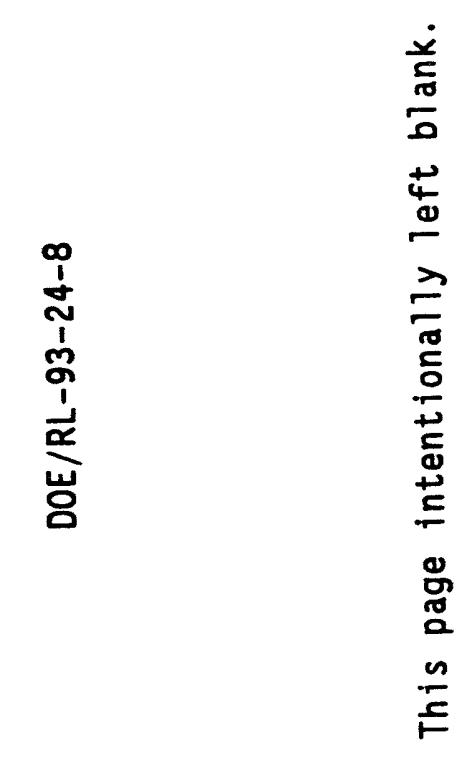

$$
\begin{aligned}
& \text { 《す } \\
& \text { 希出票 } \\
& \text { 总品 } \\
& \text { 드 } \\
& \text { 言兽茴 }
\end{aligned}
$$

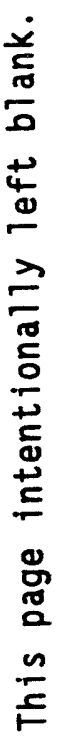

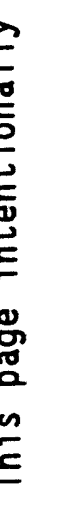




\section{TCD DATA QUALIFIERS}

OVERVIEW

REQUIREMENT
One or more data qualifiers can be supplied by the laboratory performing the analysis and/or by the person validating the results. Data qualifiers provide information about the quality of the analytical result.

Data qualifiers are one-letter codes entered in the Qualifiers field (with no delimiters).

A result record may or may not have qualifiers. The only limits on qualifiers are that there are no duplicates and that each qualifier exists in the collective list of valid qualifiers. 

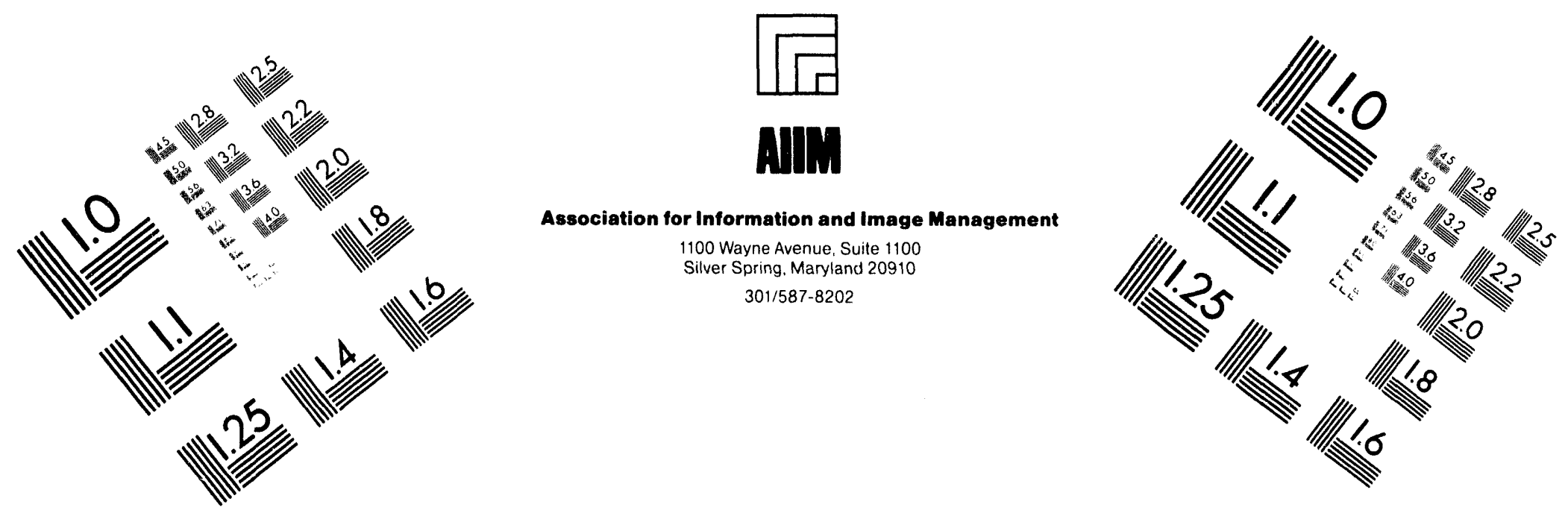

\section{Centimeter}

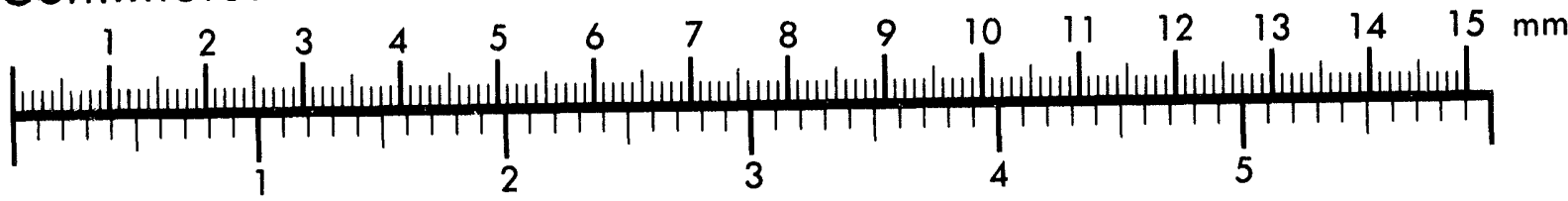

Inches
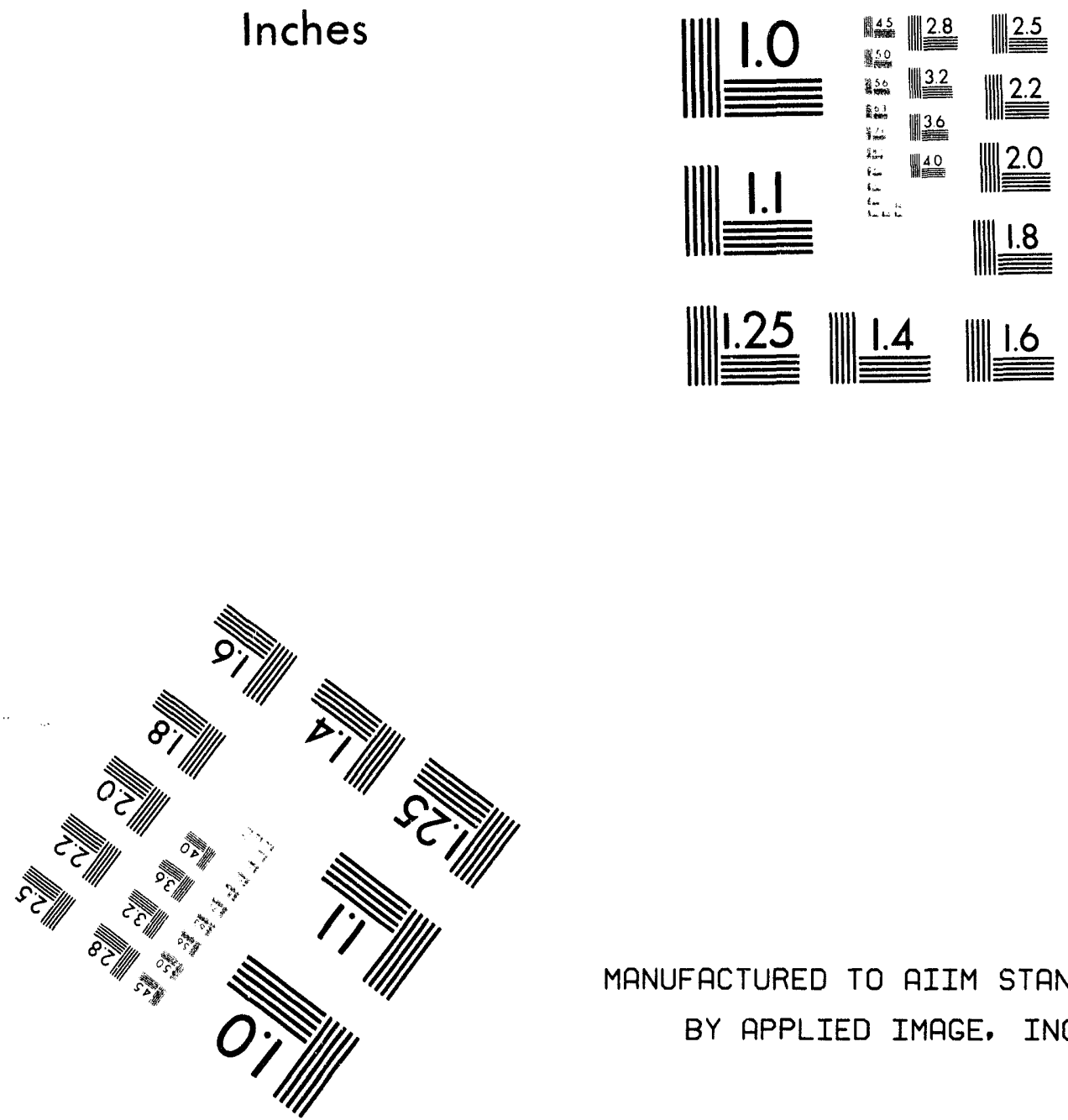

MANUFACTURED TO AIIM STANDARDS

BY APPLIED IMAGE, INC.

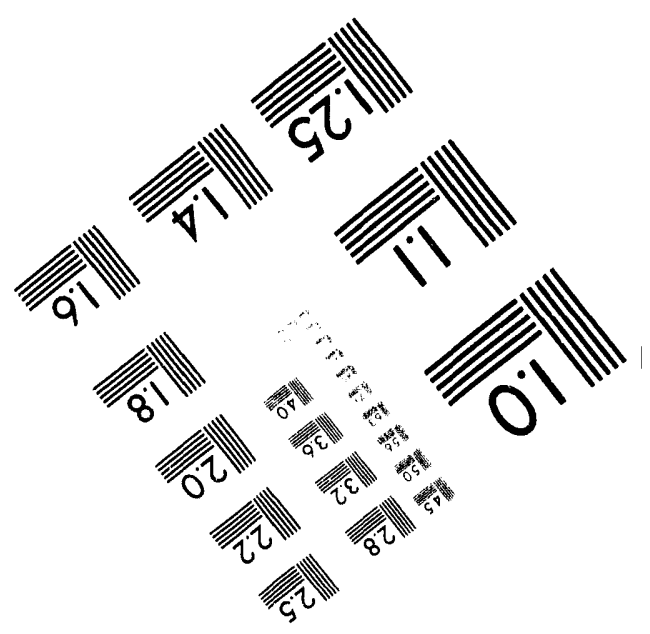



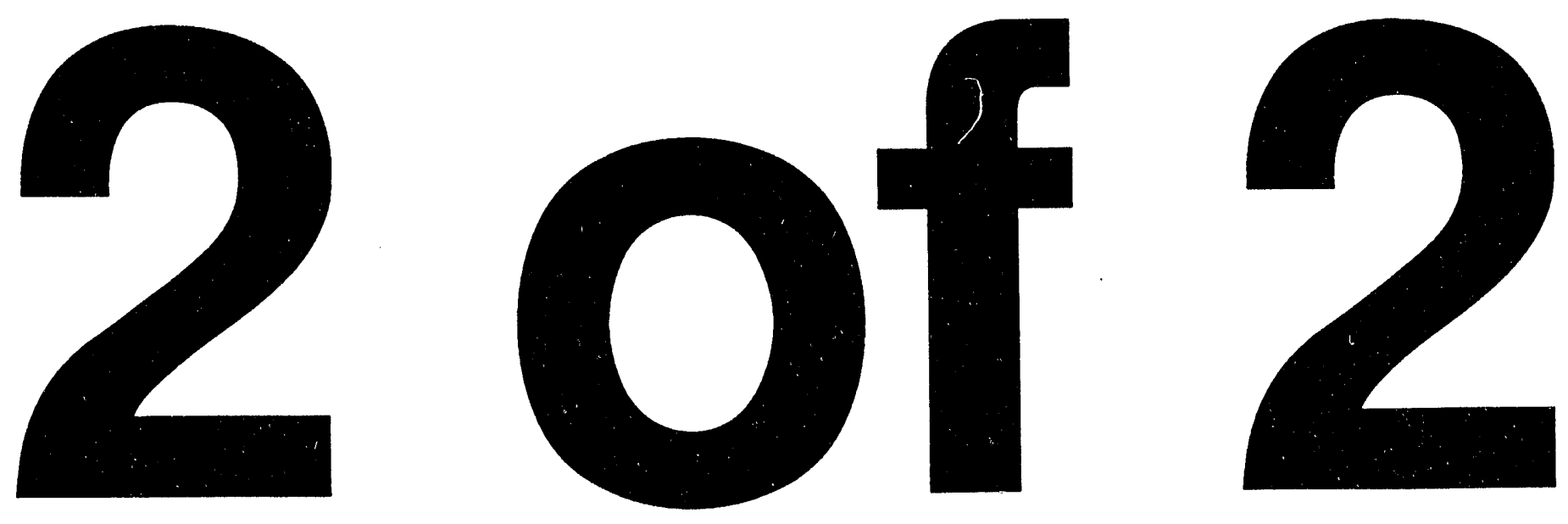
Section APPENDIX A

Page 4 of 4

Date $04 / 15 / 94$

TCD DATA QUALIFIERS

A

B

C

D

E

J

N

0

Q

R

S

U

$X$
Aldol condensation product.

Compound was found in the blank.

Concerns not requiring qualification of the data but still having a potential impact on data quality.

Analysis was performed on a diluted sample.

Quantitation was outside of the calibration range.

Associated value is an estimated quantity.

Material was not analyzed for since the sample preparation made such measurement not appropriate (e.g. Potassium in a $\mathrm{KOH} / \mathrm{Ni}$ Fusion preparation).

Measurement was over the range of the instrument.

Associated results are qualitative.

Data are unusable.

Minimum detection limit was substituted for the reported analytical result value.

Measurement was below the detection limit -- there may or may not be an associated value.

Compound was manually deleted because all requirements were not met. 
Section APPENDIX B

Page

Date

1 of 6

$04 / 15 / 94$

APPENDIX B

TCD DATA LOADING AND VALIDATION PROCEDURES 
Section APPENDIX B

Page 2 of 6

Date $\quad 04 / 15 / 94$

$\mathrm{DOE} / \mathrm{RL}-93-24-8$

CONTENTS

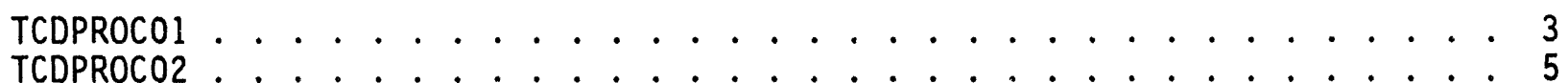


DOE/RL-93-24-8

Section APPENDIX B

Page

3 of 6

Date

$04 / 15 / 94$

TCD DATA LOADING AND VALIDATION PROCEDURES

PROCEDURE NAME

INITIAL VERSION

PURPOSE

DESCRIPTION

Procedure
TCDPROCO1

1.0 Date: $12 / 22 / 93$

This section describes the procedure used to load and verify the first three tanks-worth of data loaded into TCD.

Data from Tanks B-201, C-112, and C-109 were loaded completely manually. This was done by transcribing data from the official verified and validated data packages contained in Westinghouse Hanford Company (WHC) supporting documents (SD) obtained from WHC Unclassified Document Control. The data from these three tanks were typed directly into TCD data entry screens from the documents.

TCD data entry verification of analysis results was performed in the following manner:

1. Files containing result data were prepared from electronic spreadsheets received from the labs. For data for which no lab spreadsheet was available, result data were prepared from the documents. Each result record consisted of Sample Number, Analysis Method ID, Constituent ID, Value Type, Value Reported, Units, Qualifiers, Analys is Date, Uncertainty Value, and Uncertainty Units.

2. TCD was queried by HEIS Sample Number using SQL to obtain analogous result data from TCD.

3. The two sets of results were compared using a simple utility written for this purpose. This program produced an error report showing the discrepancies between the two files. Discrepancies reported included missing data, duplicate data, and differences.

4. Discrepancies were rectified and the comparison program was run again until all discrepancies were cleared.

5. Following TCD verification, the TCD UPLEVEL program was run against the cores associated with these 
Section APPENDIX B

Page $\quad 4$ of 6

Date

$04 / 15 / 94$

three tanks, setting the Access Level to show that the data were verified and validated. The UPLEVEL program also inserted the text, "VERIF. REF: TCDPROCOl" as the initial text of the TCD Analysis Result table Comment field.

TCD data entry verification of all other data (tanks, farms, samples, analyses, and sample relationships) was performed by printing out all records, visually inspecting them, and making appropriate corrections. This process was iteratively performed until the data were complete and accurate. 
PROCEDURE NAME

INITIAL VERSION

PURPOSE

DESCRIPTION

Procedure
TCDPROCO2

$$
1.1 \quad \text { Date: } 4 / 15 / 94
$$

This section describes the procedure used to load and verify the initial electronic data received from the labs using the initial TCD standard electronic format (SEF) translator/loader/verifier.

Data from tanks starting with S-104 were loaded using this procedure. All results loaded and subsequently verified using this procedure are so marked in TCD by having the first characters of the TCD Analysis Result table Comment field contain the text, "VERIF. REF: TCDPROC02." The source media for this electronic data is floppy disks provided by the labs to TCD.

NOTE: The labs did not rigorously control the versions of any electronic data they maintained during production of the data packages; no standard electronic format existed, nor were the labs required to deliver electronic data.

Data loading and verification used the following procedure:

1. Laboratory electronic spreadsheets were translated using a software translator into the TCD SEF.

2. The SEF was loaded into TCD using the TCD SEF loader.

3. Once loaded into TCD, a software verifier was run against the SEF; the verifier verified that all analysis and result data in the SEF existed in TCD and that each datum existed only once.

4. The source of Hanford Analytical Services Management (HASM) qualifiers is the handwritten qualifiers on the SD document resulting from HASM validation; these qualifiers are manually transcribed to an electronic document in the qualifier electronic loader format.

5. The qualifier loader/verifier was run against the electronic document prepared in step 4. 
Section APPENDIX B

Page

Date
6 of 6

$04 / 15 / 94$
$D 0 E / R L-93-24-8$

6. The UPLEVEL program was run again, setting the Access Level to show that the data were verified and validated. 


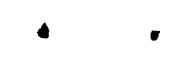

DOE/RL-93-24-8

APPENDIX C

TCD SUPPORT PROGRAMS
Section APPENDIX C

Page 1 of 4

Date $\quad 04 / 15 / 94$ 
Section APPENDIX C

Page 2 of 4

Date $\quad 04 / 15 / 94$
$D O E / F_{i L}-93-24-8$

\section{CONTENTS}

$\cdot$ 
DOE/RL-93-24-8

Section APPENDIX $C$

Page

3 of 4

Date

$04 / 15 / 94$

\section{TCD SUPPORT PROGRAMS}

INTRODUCTION

TCD includes special-purpose software programs used primarily by TCD data entry staff to make mass modifications of specific fields in TCD records.

\subsection{TCD UPLEVEL}

INTRODUCTION

The TCD UPLEVEL program changes the Access Levels of various records to make the records viewable to reflect their verification and validation status.

USING THE PROGRAM

To start the program, enter the following command:

$$
\% \text { tcd_uplevel }
$$

When the program begins, the following menu appears:

TCD UPLEVEL Program

Choose an option by number:

1. Tank Core

2. Tank Supernate

3. Tank Surface Sample

4. Sample Relations

5. Sample and Results

X. Exit.

Option:

Tank Cores

The program prompts you to enter a valid Tank Farm ID, Tank ID, and Tank Core ID. After valid IDs have been entered, the program asks for the new Access Level for the records. The program updates the Access Level on all records in the Tank Core and Tank Core Segment tables where the records have the entered Tank Farm ID, Tank ID, and Tank Core ID.

Tank Supernate

The program prompts you to enter a valid Tank Farm ID, Tank ID, and Tank Supernate Sample ID. After valid IDs have been entered, the program asks for the new Access Level for the records. The program updates the Access Level on all the records in the Tank Supernate Sample table having the entered Tank Farm ID, Tank ID, and Tank Supernate Sample ID. 
Section APPENDIX C

Page 4 of 4

Date $04 / 15 / 94$

Tank Surface Sample

Sample Relations

Sample and Results

MESSAGES AND NOTES
The program prompts you to enter a valid Tank Farm ID, Tank ID, and Tank Surface Sample ID. After valid IDs have been entered, the program asks for the new Access Level for the records. The program updates the Access Level on all the records in the Tank Surface Sample table having the entered Tank Farm ID, Tank ID, and Tank Surface Sample ID.

The program prompts you to enter a valid Sample Number and a new ficcess Level value. The program updates the Access Level on all the records in the Sample Relation table having the entered Sample Number.

The program prompts you to enter a valid Sample Number. It also asks for the Verification Method, which is the procedure number that describes how the data entry verification process was conducted. The values are currently limited to TCDPROCO1 and TCDPROCO2. These procedures are documented in Appendix $B$ of this manual. After a valid method has been entered, the program asks for the new Access Level for the records. The program updates the Access Level on all the records in the TCD Sample, TCD Analysis, TCD Analysis Result, and TCD Analysis Result Change tables having the entered Sample Number.

If the new value of the Access Level is 3 or greater, the program updates the Analysis Comment field in the TCD Analysis Result table by prefacing the existing comment with "Verif Ref:" and the Verification Method that you entered when the Access Level was updated.

The program keeps a log file of the user's entered values. This file is named "tcd uplevel.log" and is placed in the user's current defauTt directory.

If the Access Level is 3 or greater and the new Analys is Comment would be longer than the maximum 240 characters, a message is written to the log file with the Result Record Number of the appropriate record.

If the Access Level is 3 or greater and the current Analysis Comment already has the preface "Verif Ref:," then a message is written to the log file with the Result Record Number of that record. (This condition would exist if this record's Access Level was being modified a second time.)

If the current Analysis Comment contains a single quote ('), the update for that Sample Number will fail. (As of $12 / 17 / 93$, no records in production exhibited this condition.) 

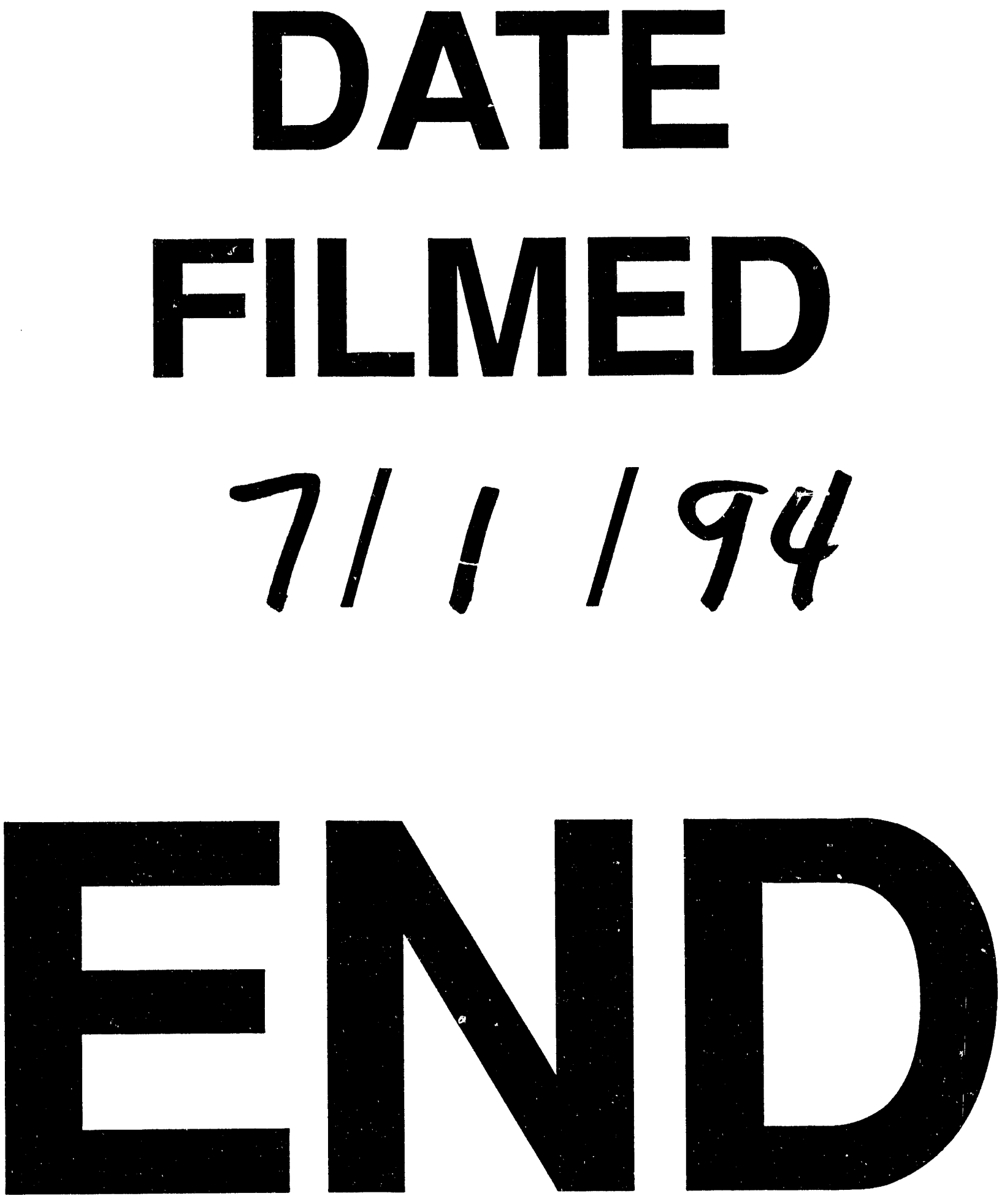
